\title{
Contribution of Recycled Alumina Waste to Cement Strength and Microstructure Development
}

\author{
Suzan S. Ibrahim ${ }^{1}$, Ayman A. Hagrass ${ }^{2}$, Tawfik R. Boulos ${ }^{1}$, Samir I. Youssef $f^{2}$, Fouad I. El-Hosiny ${ }^{3}$, Mohamed R. \\ Moharam $^{4}$ \\ ${ }^{1}$ Central Metallurgical Research and Development Institute, P.O. Box 87 Helwan, 11421 Cairo, Egypt \\ ${ }^{2}$ El-Tabbin Institute for Metallurgical Studies, Helwan, Cairo, Egypt \\ ${ }^{3}$ Faculty of Science, Ain Shams University, Cairo, Egypt \\ ${ }^{4}$ Faculty of Engineering, Azhar University, Cairo, Egypt \\ Correspondence: Suzan S. Ibrahim, Central Metallurgical Research and Development Institute (CMRDI) P.O. Box 87 Helwan, \\ 11421 Cairo, Egypt. E-mail: suzansibrahim@gmail.com
}

Received: June 20, 2018 Accepted: July 18, 2018 Online Published: July 19, 2018

doi:10.5539/ijc.v10n3p70 URL: https://doi.org/10.5539/ijc.v10n3p70

\begin{abstract}
The role of alumina waste as a reactive pozzolan for the local Portland cement has been thoroughly investigated. The results showed that the initial and final setting times of the hardened blended pastes were reduced significantly by increasing the amount of the added alumina. In addition, the compressive strength and the hydraulic property measures of the hardened blends showed progressive improvement reaching approximately $42 \%$ and $23 \%$ after the early ages of hydration (1 and 3 days), respectively. According to such conditions, these cement blends could be applied in many concrete applications, such as high speed construction, rapid repair, frost prevention, tunneling, shoring, gas and oil well cementing, that require concrete to have rapid setting and strength development abilities.

The improvement of the physico-mechanical characteristics and the hydration kinetics of the hardened blended pastes with the recycled alumina were explained after the microstructure study included the examinations of hydration product morphology and type, the thermal gravimetric (TG), the differential scanning calometry (DSC) and the differential thermo-gravimetric (DTG) thermographs analyses. The scanning electron microscope (SEM) was used to examine the microstructure and morphology of hydration products.
\end{abstract}

Keywords: aluminum scrap, cement industry, compressive strength, hydration kinetic, pozzolan material

\section{Introduction}

Portland cement mainly consists of four clinker materials: two silicates (calcium silicates hydrate $\mathrm{C}_{3} \mathrm{~S}$ and $\beta-\mathrm{C}_{2} \mathrm{~S}$ ) and two aluminates (calcium aluminates hydrate $\mathrm{C}_{3} \mathrm{~A}$ and $\mathrm{C}_{4} \mathrm{AF}$ ), and gypsum as setting additive regulator. When Portland cement is mixed with water, its phases start to hydrate. The reaction of the tri-calcium aluminate $\left(\mathrm{C}_{3} \mathrm{~A}\right)$ and the ferrite phase $\left(\mathrm{C}_{4} \mathrm{AF}\right)$ predominates at the early ages of hydration. The hydrous calcium aluminium sulfate, ettringite (AFt), is the usual hydrated product in the early ages of the hydration. The reaction of calcium silicate phases $\left(\mathrm{C}_{3} \mathrm{~S}\right.$ and $\left.\beta-\mathrm{C}_{2} \mathrm{~S}\right)$ predominates from about the time of initial set onward forming calcium silicate hydrates and $\mathrm{Ca}(\mathrm{OH})_{2},(\mathrm{Park}, \mathrm{Sun}$, Lee,\& Shin, 1999; Nehdi \& Hayek, 2005; Mobili, Belli, Giosuè, Bellezze \& Tittarelli, 2016; Federica, Elena, \& Luca, 2016; Amer \& El-Hoseny, 2017).

Durability of Portland cement concrete is defined as its ability to resist weathering action, chemical attack, abrasion, fire or another process of deterioration. In other words, cement concrete will be termed durable, when it keeps its form and shape within the allowable limits, while exposed to different environmental conditions, (Elena et al., 2016). Durability of concrete has been a major concern of civil engineering professionals. Also, it has been of considerable scientific and technological interest over the last few decades, (Park et al., 1999; Nehdi \& Hayek, 2005; Alessandra et al., 2016; Federica et al., 2016; Amer \& El-Hoseny, 2017).

Pozzolanic materials added to blended cements are siliceous or non-siliceous and aluminous materials, which by themselves have little or no cementitious value. But these materials on reacting with calcium hydroxide $\mathrm{Ca}(\mathrm{OH})_{2}$ in presence of moisture at ordinary temperature possess cementitious properties. Due to hydration of tri-calcium silicate and di-calcium silicate, calcium silicate hydrate $\left(\mathrm{CaO}, \mathrm{SiO}_{2}, \mathrm{H}_{2} \mathrm{O}\right)$ and calcium hydroxide $\mathrm{Ca}(\mathrm{OH})_{2}$ are formed. $\mathrm{Calcium}$ 
silicate hydrate is known as $\mathrm{C}-\mathrm{S}-\mathrm{H}$ gel and results to significant strength gain. On the other hand, $\mathrm{Ca}(\mathrm{OH})_{2}$ is an unwanted product having no cementitious value. It is soluble in water and leaches out making the concrete porous. Calcium hydroxide causes many other negative features in the concrete. Among these are the "efflorescence" and the "alkali silica reaction" (ASR). However this unimportant, non-cementitious water soluble calcium hydroxide can be converted to insoluble cementitious materials by adding finely divided pozzolanic material. Natural pozzolans have been used since antiquity with excellent results for production of durable concrete. Industrial by-products as pozzolanic additives are now used for the production of high-performance concrete. The fly ash, silica fume and the blast furnace slag are used to improve the resistance of concrete in aggressive environments, (Zelie, Rusie, Veza,\& Krestulovie, 2000; Morsy \& Shebl, 2007).

Increased attention to the environmental impact of ordinary Portland cement (OPC) has prompted researchers to study the optimization of alternative clinker of less construction materials. The use of such supplementary cementitious materials or pozzolans leads to a significant reduction in $\mathrm{CO}_{2}$ emissions per mass of concrete and for some additions. However, pozzolans react chemically with hydrating cement to form modified paste microstructure. In addition to their positive impact, they improve concrete mechanical properties and durability, (Erdem, Gunay, \& Donat, 2003; Hayrapetyan, Mangasaryan, Tovmasyan,\& Khachatryan, 2006; Nazari, Riahi, Shamekhi, \& Fand, 2010; Nazari \& Riahi, 2011; Arefi, Javeri, \& Mollaahmadi, 2011; Onutai, Jiemsirilers, Wada, \& Thavorniti, 2013; Farzadnia, Ali, \& demirboga, 2013; Kiachehr \& Niloofar, 2013; Amin, El-Gamal, \& Hashem, 2013; Heikal, Ismail, \& Ibrahim, 2015; Ibrahim et al., 2018).

The progress of hydration of cement can be determined by different means:

- The measurement of the amount of $\mathrm{Ca}(\mathrm{OH})_{2}$ in the paste resulted from the hydration of the silicates.

- The heat evolved by hydration.

- The specific gravity of the paste.

- The amount of chemically combined water.

- The amount of un-hydrated cement present using X-ray quantitative analysis.

- Also indirectly from the strength of the hydrated paste.

In the present work, a recycled reactive alumina was added as a cement substituent with $5 \%$ and $10 \%$ additions. The effect of the added alumina was followed up through compressive strength measures of the hydrated blended paste and through the hydration kinetics including the amount of the chemically combined water and the amount of the free lime in the paste which resulted from the hydration of the silicates. In addition, these results were explained after the microstructure study included the examinations of hydration product morphology and type, the thermal gravimetric (TG), the differential scanning calometry (DSC) and the differential thermo-gravimetric (DTG) thermographs analyses. The scanning electron microscope (SEM) was used to examine the microstructure and morphology of the produced hydration products.

\section{Experimental, Materials and Methods}

The materials that were used in this study were the ordinary Portland cement CEM I 52.5R (OPC) and aluminum hydroxide (industrial waste). The OPC was provided by EL Arish Cement Company, North Sinai, Egypt. Aluminum hydroxide was supplied from Meet Ghamr industrial wastes congregation. The aluminum hydroxide grab sample was subjected to calcination tests at different temperatures from $300^{\circ} \mathrm{C}$ to $900^{\circ} \mathrm{C}$ in a laboratory electric furnace with heating rate $15^{\circ} \mathrm{C} / \mathrm{min}$. for various firing times. The produced alumina was ground using stirring mill at $1700 \mathrm{rpm}$ for $3 \mathrm{hrs}$ to reach $\mathrm{D}_{50}$ and $\mathrm{D}_{90}$, the mean particle size of 4.6 and 24.4 micron, respectively. OPC-alumina blends were prepared by substituting $5 \%$ and $10 \%$ alumina at the expense of cement. The dry blending samples were mechanically stirred for $3 \mathrm{hrs}$. using a porcelain mixer to attain complete homogeneity, and then they were kept in airtight containers for further investigation.

The needed water for the normal consistency as well as the initial and final setting times were measured using a Vicat apparatus, (El-Diadamony, Amer, Sokkary, \& El-Hoseny, 2016). The dry mixtures were mixed with water for about 3 min. The pastes were then molded into cubic specimens $(2.54 \mathrm{~cm} \times 2.54 \mathrm{~cm} \times 2.54 \mathrm{~cm})$ by using stainless steel cubic moulds. Immediately after molding, the samples were cured at about $100 \%$ relative humidity at room temperature for the first 24 hours in order to attain the final setting of the specimens, (Abo-El-Enein, Abbas, \& Ezzat, 2010; Abo-El-Enein et al., 2014). The hardened cement pastes were then removed from the moulds and cured under tap water. The applied curing time intervals were 1, 3, 7, 14 and 28 days of hydration. The stopping of the hydration process was performed on the crushed cubic specimens after the compressive strength determination. The stopping solution was composed of methyl alcohol and acetone (1:1 by volume), (The Egyptian specification, 2010). The samples were then dried at $80^{\circ} \mathrm{C}$ for three hrs. in $\mathrm{CO}_{2}$-free atmosphere and were kept in desiccators for further investigation. Kinetics of the hydration process was studied throughout the determination of the chemically-combined water and the free lime 
contents measures for the hardened specimens at different intervals times of hydration (Abo-El-Enein, Abbas, \& Ezzat, 2010; Abo-El-Enein et al., 2014). The phase analysis of the dry hardened specimens was conducted using X-ray diffractometer, model Bruker axs, D8 Advance, where the DSC thermal behavior was investigated using a DSC-50 instrument from Shimadza (Japan) with a heating rate of $10^{\circ} \mathrm{C} / \mathrm{min}$. The hardened freshly fractured specimens were coated with a thin film of gold metal under vacuum evaporator with cathode rays and directed to the microstructure pictures using a FEI Inspect S50 scanning electron microscope.

\section{Results and Discussion}

\subsection{Samples Characterization}

The chemical analysis of the aluminum hydroxide grab sample indicated that the sample was relatively high- grade aluminum hydroxide of content reaching $98.29 \% \mathrm{Al}_{2} \mathrm{O}_{3}$ with trace amounts of silica, sodium oxide, and iron oxide, Table 1. The X-ray diffraction patterns of the sample indicated that the sample was pure gibbsite mineral $\mathrm{Al}(\mathrm{OH})_{3}$, Figure 1. The particle size distribution of the grab head sample showed that the $\mathrm{D}_{50}$ and $\mathrm{D}_{90}$ of the sample were reaching 32 and 97 micron, respectively.

The thermal analysis DTA-TG curves of the grab sample showed a weak endothermic peak at $100^{\circ} \mathrm{C}$ indicating the evaporation of the physically adsorbed water, Figure 2. This was followed by the thermal decomposition of the aluminum hydroxide through three endothermic reactions. The first reaction was the gibbsite-boehmite $(\mathrm{AlOOH})$ transformation in the temperature range $220-280^{\circ} \mathrm{C}$. The second reaction was the decomposition of the residual gibbsite into oxides between $280{ }^{\circ} \mathrm{C}$ and $390{ }^{\circ} \mathrm{C}$. The third reaction was the decomposition of boehmite above $480{ }^{\circ} \mathrm{C}$ to alpha and gamma alumina, which were converted into crystalline transitional oxides at $800{ }^{\circ} \mathrm{C}$ during exothermic reactions and further into corundum, (Al'myasheva, Korytkova, Maslov,\& Gusarov, 2005; Kazakov, Sokolov,\& Tsiporina, 2013; Chukin \& Seleznev, 1989; Mardilovich, Trokhimets, Zaretskii,\& Kupchenko, 1985; Onutai, Jiemsirilers, Wada,\& Thavorniti, 2014; Hayrapetyan, Mangasaryan, Tovmasyan,\& Khachatryan, 2006; Gitzen, 2007; Kristály \& Szücs, 2013). In this study, the boehmite phase was considered the active alumina and abbreviated as "A". However, the total weight loss of the sample throughout the temperature range from room temperature to $1000{ }^{\circ} \mathrm{C}$ was approximately $35 \%$, Figure 2 . The microstructure pictures of the produced alumina indicate the fibrous structure of the sample with a high aspect ratio reaching 35, with a fiber mean diameter 1 micron, Figure 3.

The results of the calcination tests of the aluminum hydroxide grab sample, Table 2, showed increasing in the sample weight loss values with increasing the burning temperatures due to formation of variety of polymorph forms of alumina until it reached the $\alpha-\mathrm{Al}_{2} \mathrm{O}_{3}$ phase at $1200{ }^{\circ} \mathrm{C}$, Figure 4 , (Al'myasheva et al., 2005). The calcined product at $500{ }^{\circ} \mathrm{C}$ for 4 hrs showed a phase of amorphous structure, Figure 5. This product was used in this study as the reactive alumina pozzolan.

Table 1. Chemical Analysis of the Aluminum Hydroxide Grab Sample

\begin{tabular}{cccc}
\hline Oxide & $\%$ & Oxide & $\%$ \\
\hline $\mathrm{Al}_{2} \mathrm{O}_{3}$ & 98.29 & $\mathrm{SO}_{3}$ & 0.03 \\
$\mathrm{SiO}_{2}$ & 0.72 & $\mathrm{CaO}$ & 0.16 \\
$\mathrm{Na}_{2} \mathrm{O}$ & 0.39 & $\mathrm{TiO}_{2}$ & 0.10 \\
$\mathrm{Fe}_{2} \mathrm{O}_{3}$ & 0.25 & $\mathrm{Cr}_{2} \mathrm{O}_{3}$ & 0.016 \\
$\mathrm{~K}_{2} \mathrm{O}$ & 0.04 & & \\
\hline
\end{tabular}

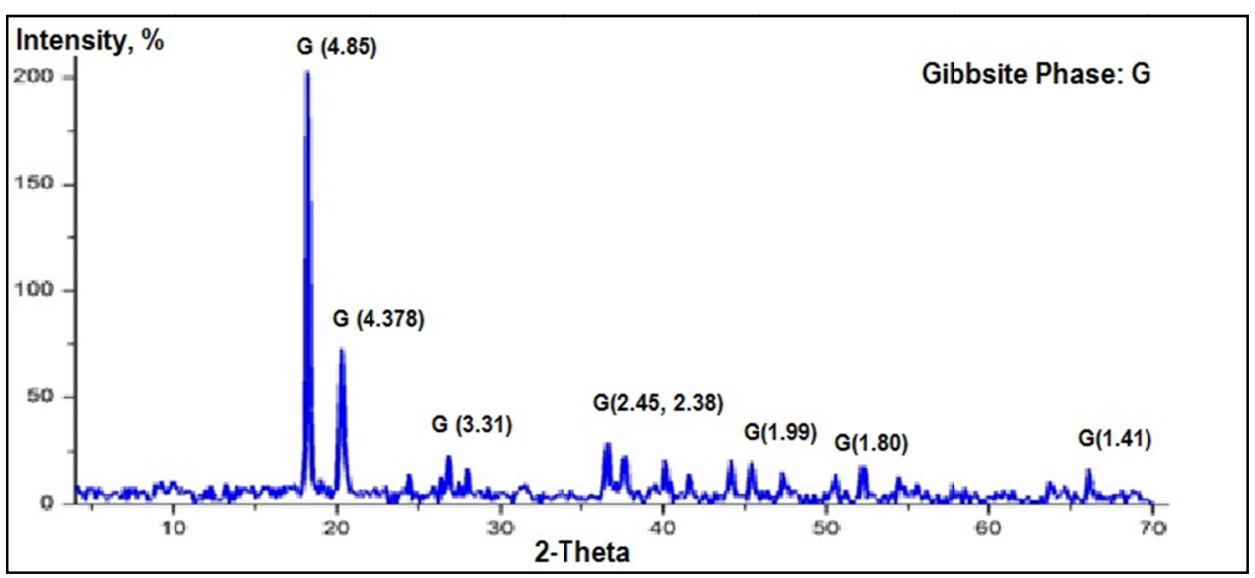

Figure 1. XRD Pattern of the Aluminum Hydroxide Grab Sample 


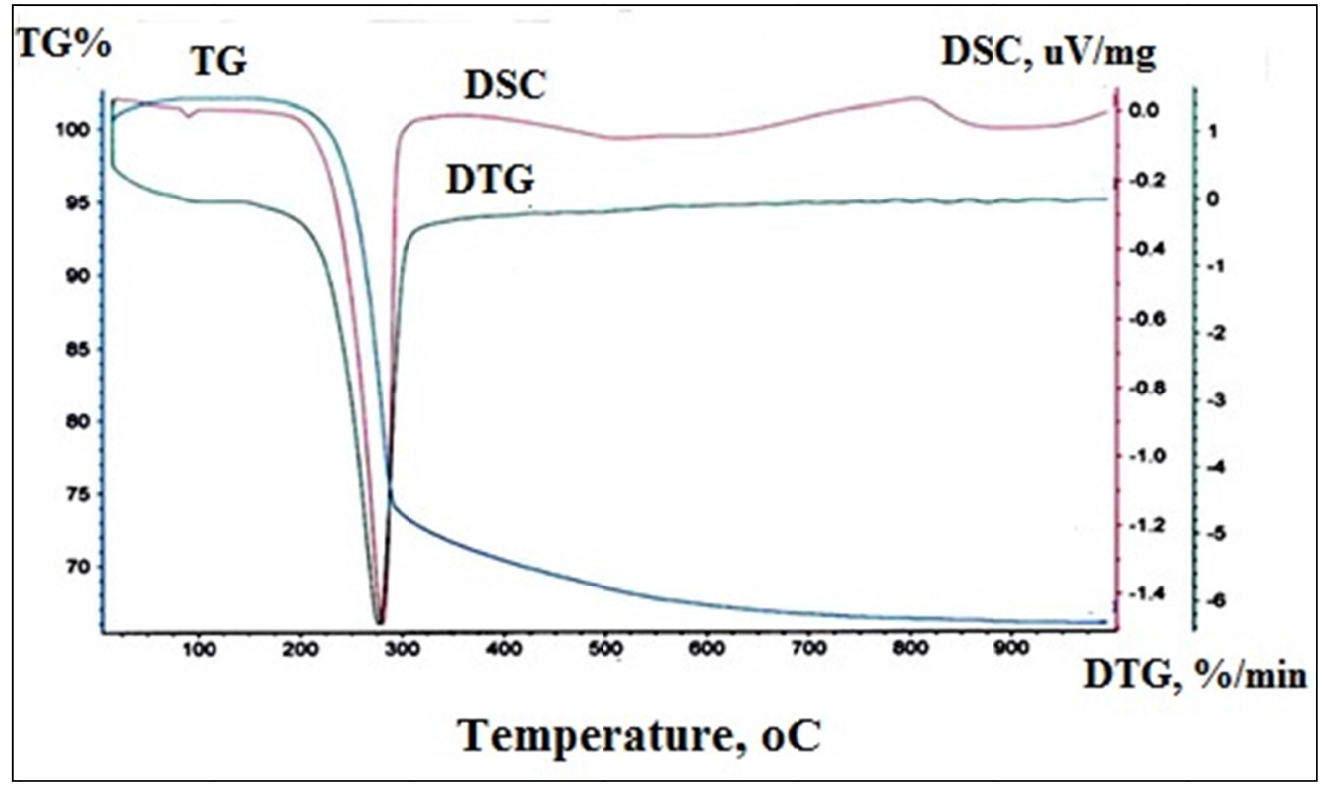

Figure 2. The Tthermal Analysis of the Aluminum Hydroxide Grab Sample
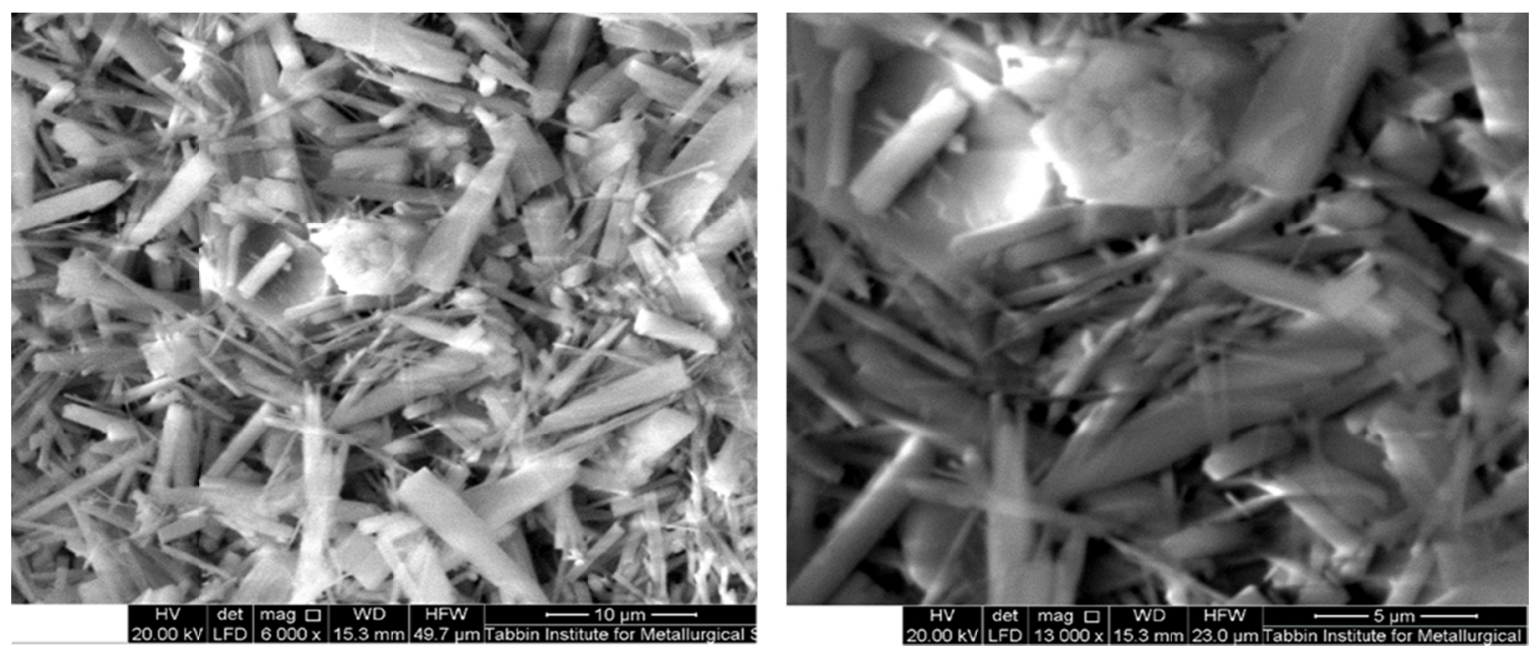

Figure 3. Scanning Electron Microscope Pictures of the Aluminum Hydroxide Grab Sample

Table 2. The Loss in Weight $\%$ Measures after Calcination at Different Temperatures and Firing Times

\begin{tabular}{cccccccc}
\hline Time, hr. & $300{ }^{\circ} \mathrm{C}$ & $400{ }^{\circ} \mathrm{C}$ & $500{ }^{\circ} \mathrm{C}$ & $600{ }^{\circ} \mathrm{C}$ & $700{ }^{\circ} \mathrm{C}$ & $800{ }^{\circ} \mathrm{C}$ & $900{ }^{\circ} \mathrm{C}$ \\
\hline 1 & 21.35 & 24.70 & 27.30 & 28.86 & 29.91 & 31.43 & 32.63 \\
3 & 21.78 & 25.20 & 28.70 & 30.60 & 30.90 & 32.14 & 32.76 \\
4 & 22.15 & 26.00 & 29.20 & 31.00 & 31.70 & 31.94 & 32.79 \\
\hline
\end{tabular}




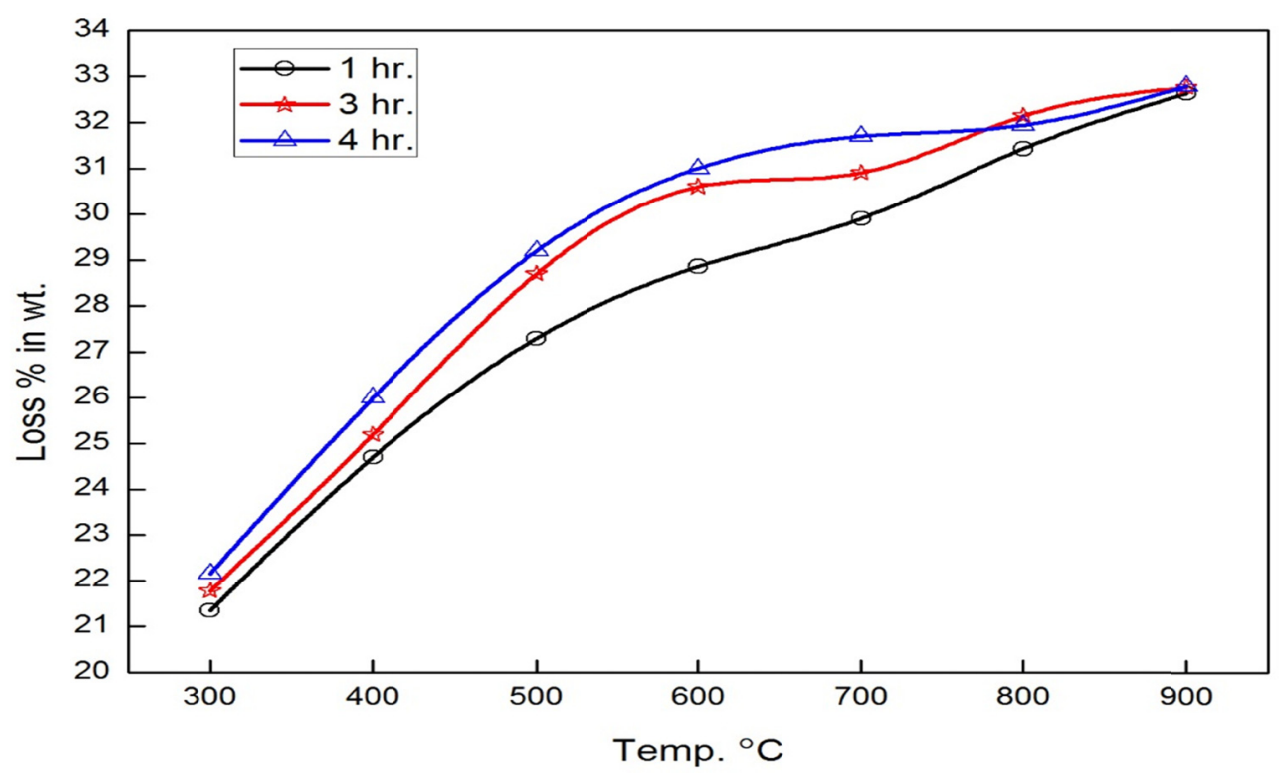

Figure 4. Loss in Wt. \% Measures after Calcination at Different Temperatures and Firing Times

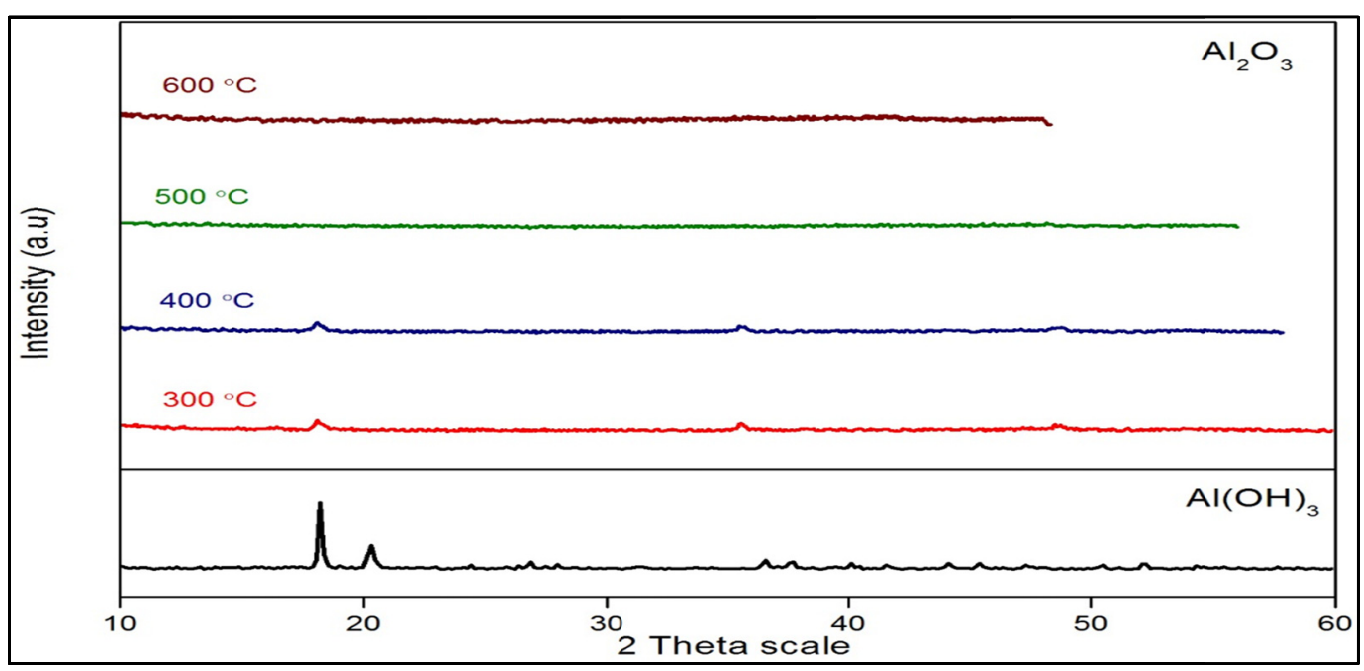

Figure 5. XRD Patterns of Fired Products at Different Temperatures for 4 Hours

The produced alumina was ground using stirred ball mill at $1700 \mathrm{rpm}$ for $3 \mathrm{hrs}$. The particle size analysis of the ground alumina product showed that $\mathrm{D}_{50}$ and $\mathrm{D}_{90}$ of the product reached 4.60 and 24.40 micron, respectively. The microstructure of the sample showed a nodular shape, Figure 6. 


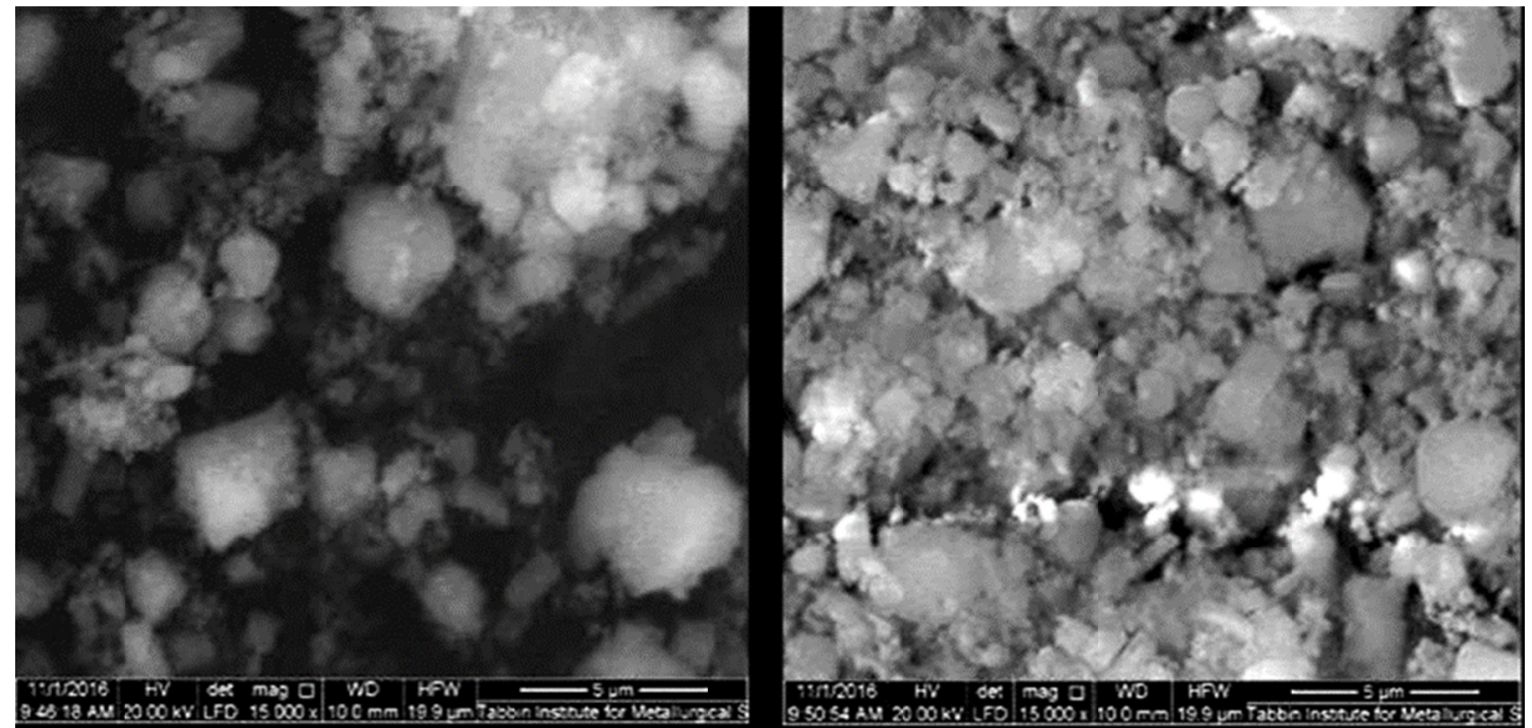

Figure 6. The Scanning Electron Microscope Pictures of the Produced Alumina

\subsection{The Standard Water Consistency and the Setting Times Results of the Hardened Neat and Blended Pastes}

The results of the standard water consistency ratios $(\mathrm{W} / \mathrm{C})$ of the hardened neat and blended pastes containing alumina showed increasing in the standard water of consistency from 27 in the hardened neat OPC to 29 and 33.5 in the $5 \%$ and $10 \%$ hardened OPC- alumina pastes, respectively, Figure 7. This could be explained after the reactivity of the added alumina that needed more water of consistency. On the other hand, the results of the initial and final setting times showed significant reduction from 110 and 180 in the neat OPC to 80 and 140 in case of 5\% alumina and 30 and 50 in case of 10\% alumina, Figure 8 . These results were attributed to the rapid hydration reactions between alumina and calcium hydroxide that was produced after the cement hydration, forming hydrated products, mainly calcium aluminates hydrate (CAH).

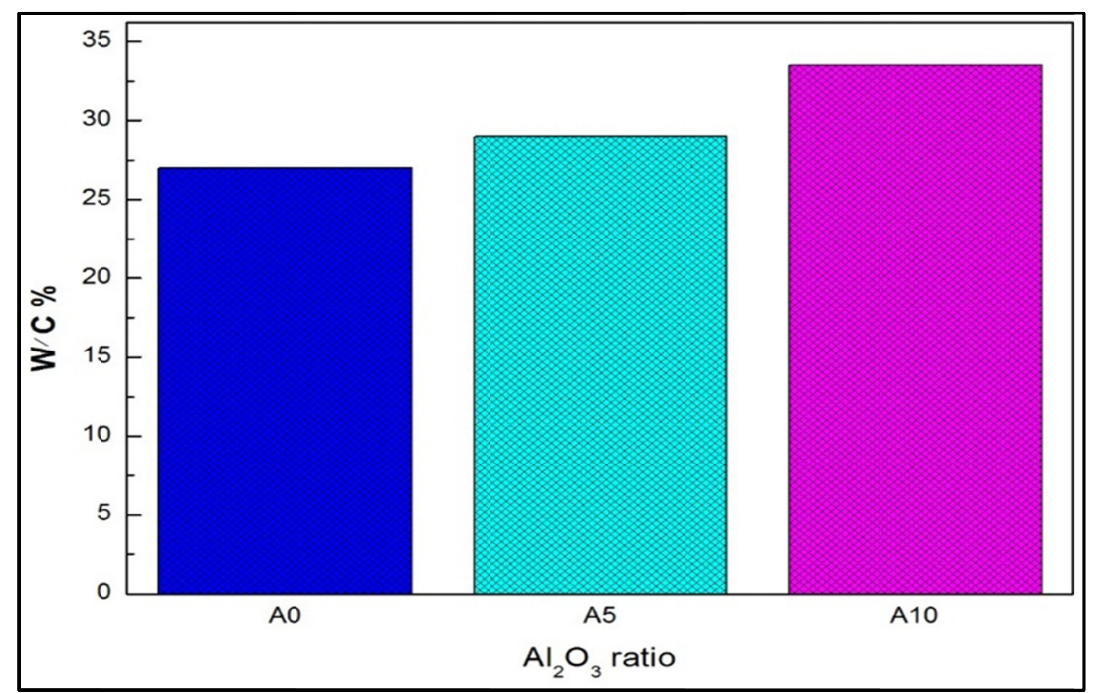

Figure 7. The Standard Water of Consistency of the Hardened Neat OPC and OPC- Containing Alumina 


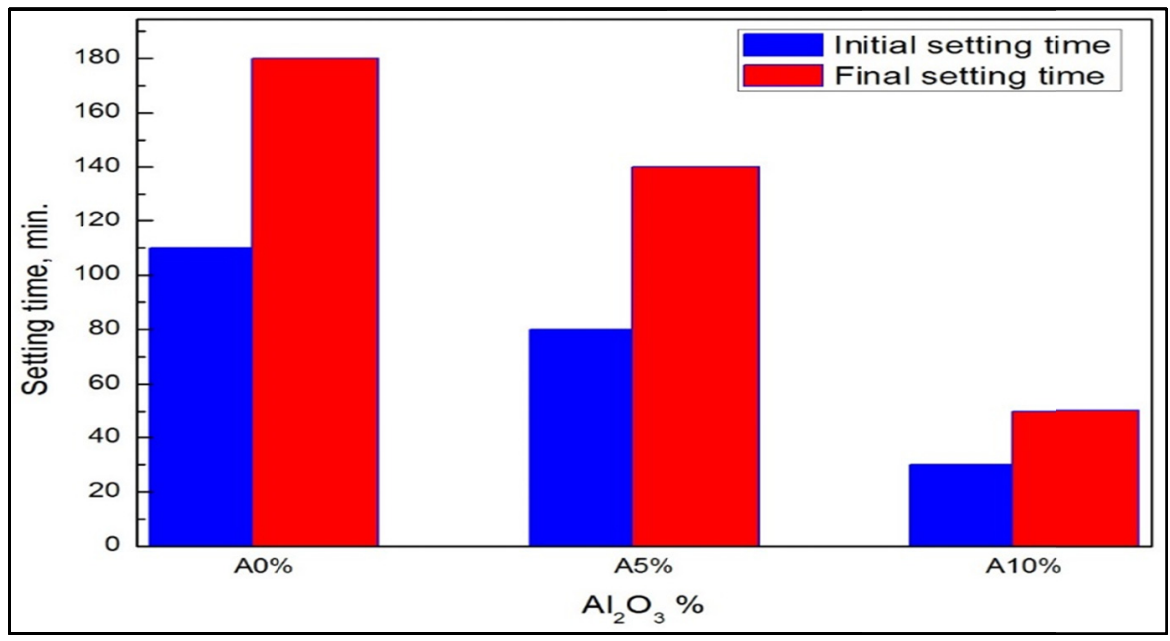

Figure 8. The Vicat Initial and Final Setting Times of the Hardened Neat OPC and OPC- Containing Alumina

\subsection{The Compressive Strength Measures Results}

The compressive strength results of the hydrated neat and blended cement pastes showed that the hydrated OPC-A5 had an appreciable increase in the compressive strength value reaching 45.20 MPa than that of the hydrated neat OPC paste reaching $31.70 \mathrm{MPa}$ during the early ages of hydration, Table 3 . This increase was reaching $42.59 \%$ compared to the compressive strength measure of the hardened neat paste, Table 3. With the increase of the hydration aging, the compressive strength measures of the OPC-A5 paste showed sharp deterioration till it was reaching $85.70 \mathrm{MPa}$ compared to that of the hardened neat paste reaching $82.00 \%$ (with an increase reaching $2.76 \%$ ) at the 14 days of hydration, Table 3 . At the 28 days of hydration, the compressive strength measure of the hardened OPC-A5 reached $98.20 \mathrm{MPa}$, where the compressive strength measure of the hardened neat OPC reached 101.30 MPa (i.e. with a decrease in the compressive strength reaching $3.06 \%$ ), Table 3 .

In addition, the hydrated OPC-A10 showed an increase in its compressive strength measures through the early ages of hydration ( 1 and 3 days of hydration) reaching $35.70 \mathrm{MPa}$ and $67.30 \mathrm{MPa}$ with increase reaching $12.62 \%$, and $3.22 \%$, respectively, Table 3 . These increasing values were followed by gradual decrease in the compressive strength measures reaching 70.80, 78.01 and $88.70 \mathrm{MPa}$ compared to the compressive strength measures of the hardened neat OPC paste reaching $72.60,82.00$ and $101.30 \mathrm{MPa}$ at the 7,14 , and 28 days of hydration, respectively, Table 3.

The increase in the compressive strength measures of the ordinary Portland cement by adding $5 \%$ alumina at the early ages of hydration ( 1 and 3 days of hydration) was attributed to the rapid acceleration of the hydration process of the OPC to form the calcium silicate hydrates $\mathrm{C}_{3} \mathrm{~S}_{2} \mathrm{H}_{3}$ gel (tobermorite), which filled up the pores of the loose net structure around the cement particles, and hence decreased the porosity and increased the bulk density of interfacial transition zone (ITZ) resulting in an increase in the compressive strength of the hydrated OPC-A5\% paste, (Li, Lima, Chunb,\& Ryou, 2013). In addition, during the cement hydration process both AFt and AFm can be produced directly during hydration process at early stages of hydration. After adding alumina into the Portland cement, the sulfate-to- aluminate ratio decreased drastically and AFm was form quickly, (Han, Wang, Shi,\& Wang, 2014). However, this appreciable increase in the mechanical characteristics of the hardened OPC-A $5 \%$ in the early hydration ages is very useful in many concrete applications, such as high- speed construction, rapid repair, frost prevention, tunneling, shoring, gas and oil well cementing. This requires concrete to have rapid setting and strength development abilities.

The transformation of calcium aluminate hydrate from the metastable hexagonal form (AFt) to the stable cubical form (AFm) is accompanied with a change in the density and size of the crystals leading to decrease in the strength of the cement paste at the late ages of hydration. This decrease in the strength of the cement paste is due to loosening the adhesion and cohesion in the microstructure and the increase in the porosity of the hardened cement paste.

It is important to mention that the calcium silicate compounds $\left(\mathrm{C}_{3} \mathrm{~S}\right.$ and $\left.\mathrm{C}_{2} \mathrm{~S}\right)$ are the most important compounds responsible for the strength of the cement paste body. The tricalcium silicate $\mathrm{C}_{3} \mathrm{~S}$ contributes most to the strength development during the first four weeks. Meanwhile, the di-calcium silicate $\mathrm{C}_{2} \mathrm{~S}$ influences the gain in strength from 4 weeks onwards. At the age of about one year, the two compounds contribute approximately equal to ultimate strength. Additionally, the decreasing in the compressive strength values of the hardened OPC-A10 was attributed to the excess of the added alumina which created a dilution in the hydration products that led to pronounce weakening in the body of the pastes. The compressive strength measures for the hardened neat and the blended OPC-A5 and OPC-A10 pastes are illustrated in Figure 9. 
Table 3. Compressive Strength Measures of the Hardened Neat OPC and OPC-A Pastes at Different Hydration Ages

\begin{tabular}{cccc}
\hline Age of hydration (days) & \multicolumn{2}{c}{$\begin{array}{c}\text { Compressive strength, } \\
\text { (MPa) }\end{array}$} \\
& OPC & OPC-A5 & 42.59 \\
3 & 31.70 & 45.20 & 19.33 \\
7 & 65.20 & 77.80 & 11.96 \\
14 & 72.60 & 81.30 & 4.51 \\
28 & 82.00 & 85.70 & -2.76 \\
& 101.30 & 98.20 & \multicolumn{2}{c}{ Compressive strength, } \\
Age of hydration (days) & & \multicolumn{2}{c}{ (MPa) } \\
& & OPC-A10 & -2.62 \\
3 & OPC & 35.70 & -2.48 \\
7 & 31.70 & 67.30 & -4.83 \\
14 & 65.20 & 70.80 & -12.44 \\
\hline
\end{tabular}

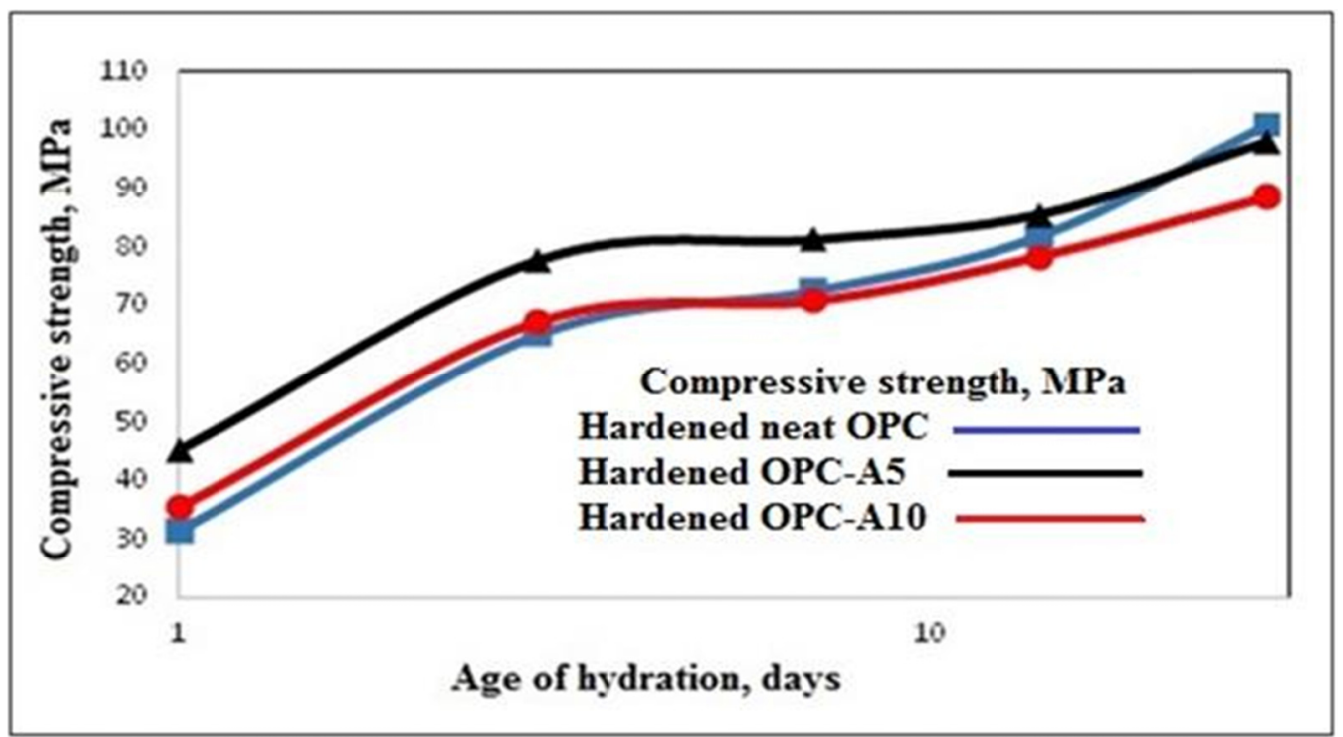

Figure 9. Compressive Strength Measures versus the Age of Hydration for the Neat OPC and the OPC-A Hardened Pastes

The main hydration products of the hardened OPC-A5 paste at the 28 days of hydration were mainly the amorphous microcrystalline calcium aluminate hydrates $(\mathrm{CAH})$, calcium hydroxide $(\mathrm{CH})$ and calcium aluminosilicate hydrates (CASH). The intensity of $\mathrm{CH}$ peaks of the hardened OPC-A5 was lower than that in case of the neat OPC (A0). This was due to the consumption of calcium hydroxide $\mathrm{CH}$ with the added alumina through a pozzolanic reaction. Additionally, the calcium carbonate peaks in case of the hardened OPC-A $\%$ is larger than that in case of neat paste due to more consumption of calcium hydroxide and its reaction with carbon dioxide forming more $\mathrm{CaCO}_{3}$, Figure 10. In addition, the intensity of the hydration products of the calcium silicate hydrates $(\mathrm{CSH})$ and calcium aluminate silicate hydrates (CASH) of the hardened OPC-A5 was larger than in case of the neat OPC due to the increase of the hydration progress and the production of more calcium aluminosilicate hydrates CASH (Aft and AFm), Figure 10. 


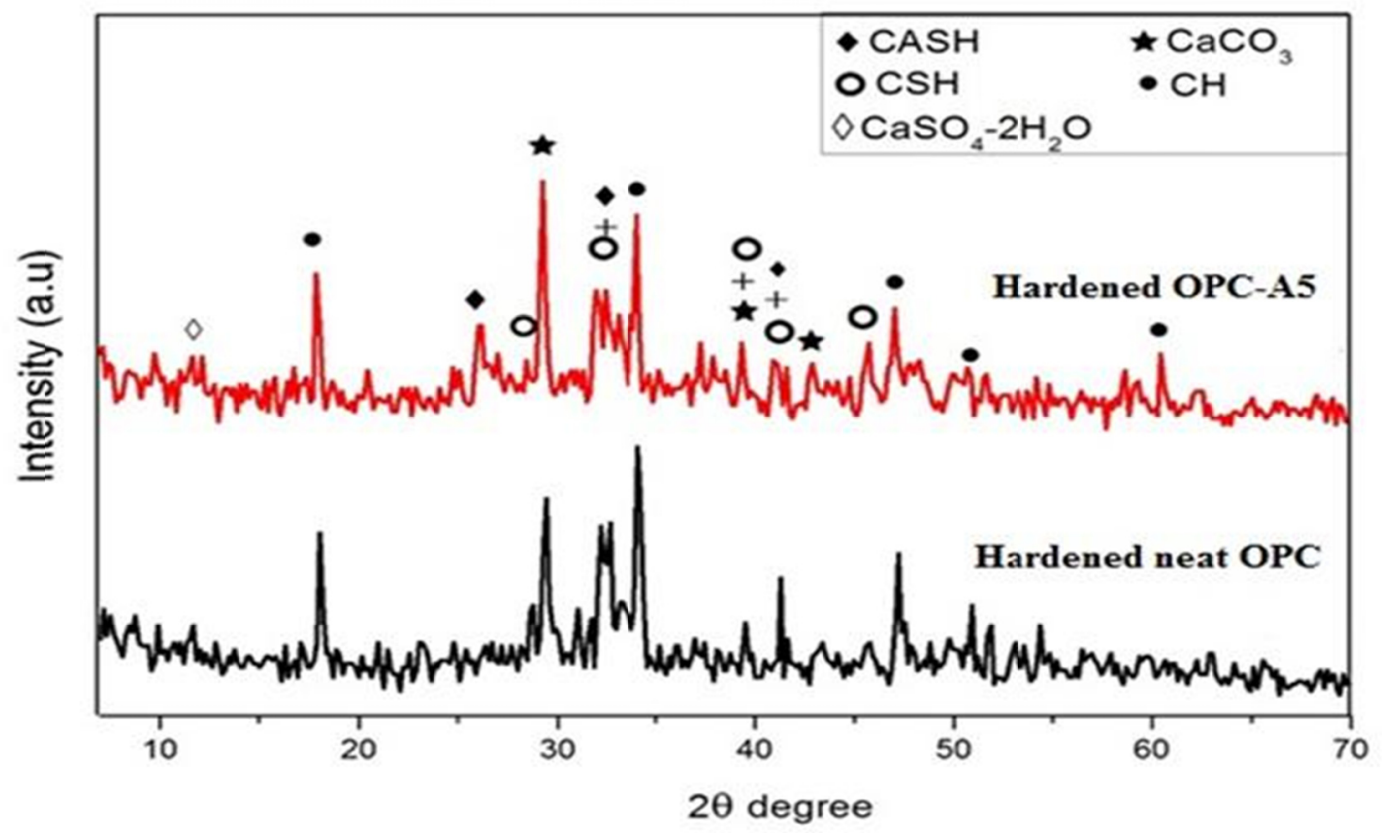

Figure 10. The X-ray Diffraction Patterns of the Hardened Cement Pastes of the Neat OPC and the Hardened OPC-A5 after 28 Days of Hydration

The microstructure picture of the neat OPC paste hydrated after 28 days is shown in Figure 11. The formation of the crumpled fibrous particles of tobermorite-like CSH phase was indicated as the dominant hydration product, Figure 11A. In addition, the calcium aluminate hydrates and the calcium hydroxide (portlandite) of hexagonal structures were shown deposited in the originally water-filled spaces as well as the unhydrated cement grains, Figure 11A. In case of the microstructure pictures of the hardened OPC-A5 paste after 1day of hydration, the complete absence of the calclium hydroxide (portlandite) could be noticed, in addition to the formation of the tabular mono- calcium sulfoaluminate hydrates (AFm), Figure 11B.

$[\mathrm{A}]$

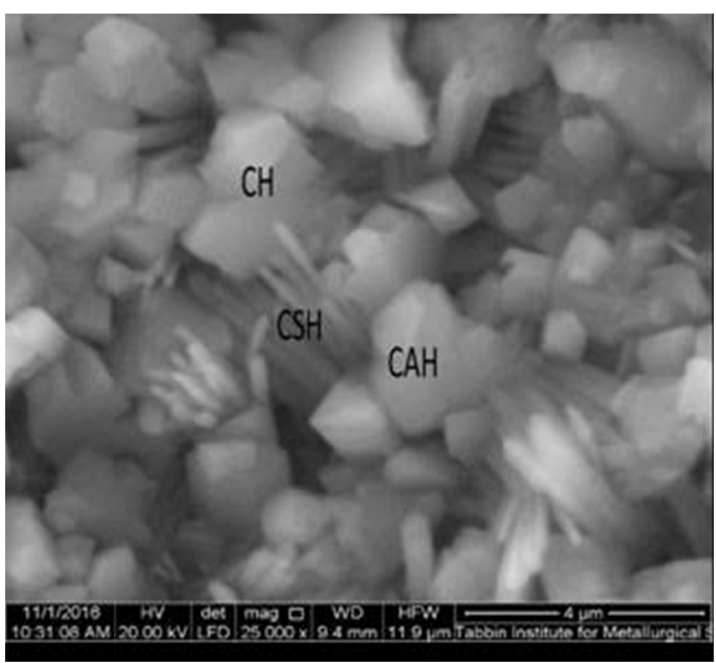

[B]

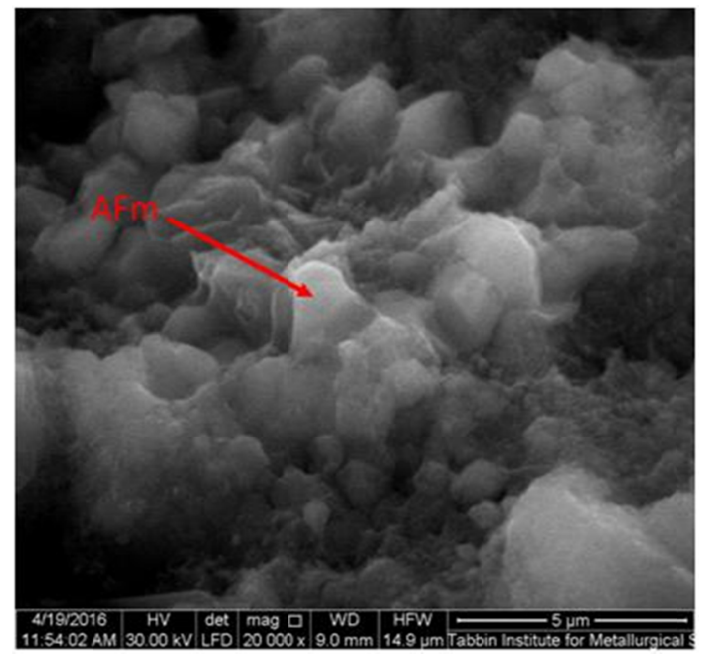

Figure 11. The SEM Microstructure Pictures of [A] the Hardened Neat OPC Paste after 28 Days of Hydration and [B] the Hardened OPC-A5\% Paste after 1 Day of Hydration

\subsection{The Hydration Kinetic Measures}

The results of the chemically combined water content measures versus the different ages of hydrations for the hardened OPC-A5 and OPC-A10 pastes showed remarkable higher chemically combined water content values than that of the hardened neat OPC indicating fast hydration reactions took place from just the time of mixing up to 1 day of hydration, Table 4. At this early hydration stage, alumina reacted with calcium hydroxide which was formed after the cement 
hydration, leading to the formation of secondary hydrated products, mainly calcium aluminate silicate hydrates as shown in the following reactions:

$$
\begin{aligned}
& \mathrm{C}_{3} \mathrm{~S} / \mathrm{C}_{2} \mathrm{~S} \text { (clinker) }+\mathrm{H}_{2} \mathrm{O} \text {----> Calcium Silicate Hydrates }(\mathrm{C}-\mathrm{S}-\mathrm{H})+\mathrm{Ca}(\mathrm{OH})_{2}------- \\
& \mathrm{Ca}(\mathrm{OH})_{2}+\left(\mathrm{Al}_{2} \mathrm{O}_{3}\right) \text {--- }>\mathrm{CSH}\left(2^{\mathrm{ry}} \text { hydration product }\right)+\mathrm{C}_{2} \mathrm{ASH}_{8}, \mathrm{C}_{4} \mathrm{AH}_{13}, \mathrm{C}_{3} \mathrm{AH}_{6}-----
\end{aligned}
$$

These reactions led to an increase in the chemically combined water content $(\mathrm{Cw})$ measures of the hardened OPC-A pastes. Accordingly, the increase in the $(\mathrm{Cw})$ could be considered as an indicator for the acceleration of the hydration reactions due to the reactivity of the added alumina. By time, the formation of these hydration products shielded the cement grains in the bulk of the paste that caused slowing in the hydration reactions rate. The chemically combined water content $(\mathrm{Cw})$ measures decreased from 12.41 and 13.97 at the 1 day hydration for the hardened OPC-A5 and OPC-A10 with increase reaching $59.10 \%$ and $97.10 \%$ compared with the hardened neat paste measure reaching 7.80 to 16.57 and 17.38 at the 7 day hydration for the hardened OPC-A5 and OPC-A10 with increase reaching $4.04 \%$ and $7.59 \%$ compared with the hardened neat paste measure reaching 16.10, Table 4. This decrease in the chemically combined water measure at the 7 days of hydration was followed by another increase up the 14 days of hydration to reach 18.55 and 19.10 at the 28 days of hydration for the hardened OPC-A5 and OPC-A10 with increase reaching $12.56 \%$ and $15.90 \%$ compared with the hardened neat paste measure reaching 16.48 , Table 4 . The chemically combined water content $(\mathrm{Cw})$ measures for the hardened neat and the blended OPC-A5 and OPC-A10 pastes are illustrated in Figure 12.

Table 4. The Chemically Combined Water Measures of the Hardened Neat and Blended Pastes at Different Hydration Ages

\begin{tabular}{cccc}
\hline \multirow{2}{*}{ Age of hydration (days) } & \multicolumn{3}{c}{ Combined water content, } \\
& OPC & OPC-A5 & Increase, \% \\
\hline 1 & 7.80 & 12.41 & 59.10 \\
3 & 13.50 & 15.80 & 17.04 \\
7 & 16.10 & 16.75 & 4.04 \\
14 & 16.25 & 17.72 & 9.05 \\
28 & 16.48 & 18.55 & 12.56 \\
& & Combined water content, & Increase, \% \\
Age of hydration (days) & OPC & OPC-A10 & 79.10 \\
1 & 7.80 & 13.97 & 21.77 \\
3 & 13.50 & 16.44 & 7.95 \\
7 & 16.10 & 17.38 & 12.49 \\
14 & 16.25 & 18.28 & 15.90 \\
28 & 16.48 & 19.10 & \\
\hline
\end{tabular}

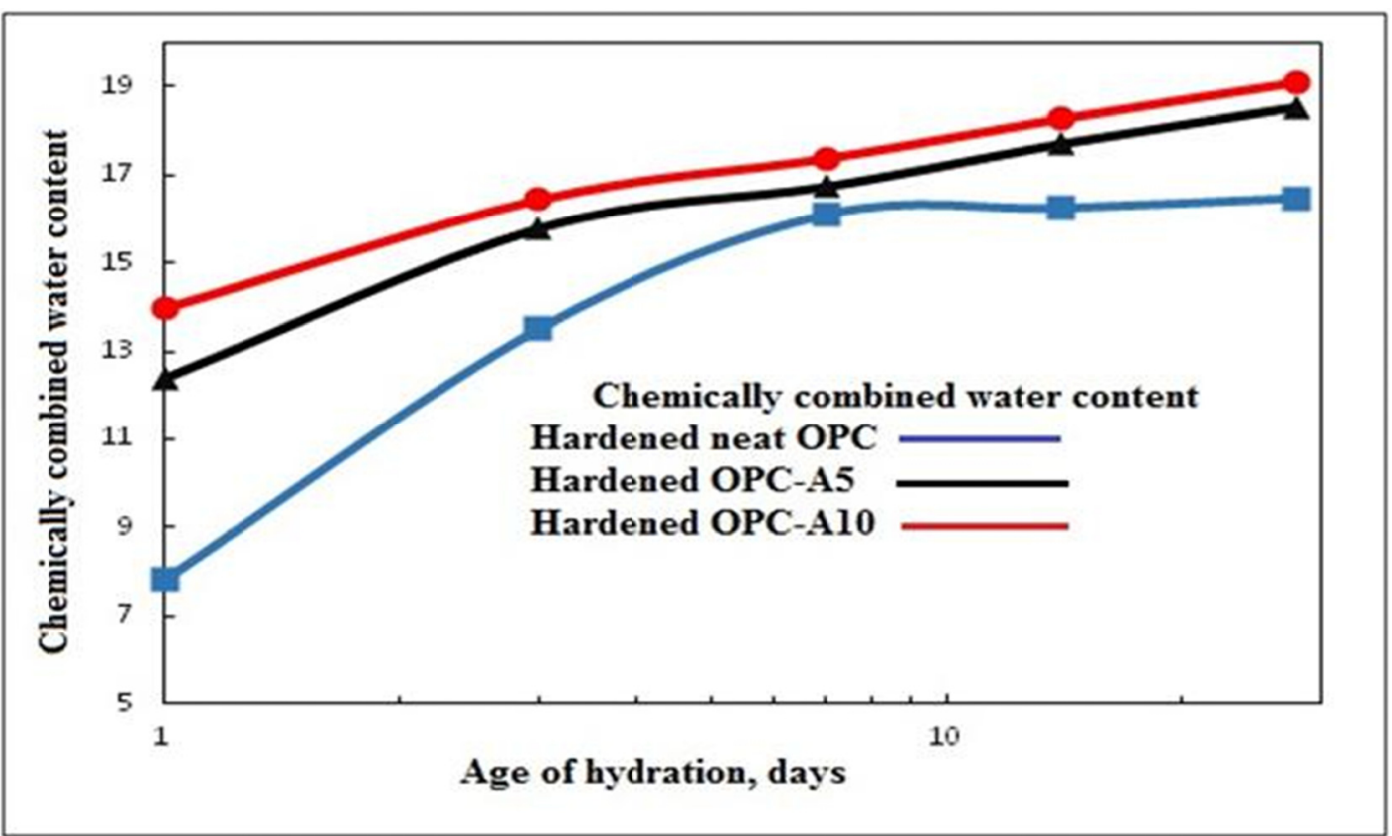

Figure 12. The Chemically Combined Water Content of the Hardened Neat and Blended Pastes versus the Age of Hydration

The free lime content measures showed increase with increasing the age of hydration for the hardened neat OPC paste indicating the continuous liberation of the free lime $(\mathrm{CH})$ throughout the different hydration ages, Table 5. On the other 
hand, the observed free lime contents for the hardened OPC-A5 and OPC-A10 pastes showed decrease throughout all ages of hydration, Table 5, which indicated that as the percentage of alumina replacement increased, the free lime content decreases as a result of increasing the consumption rate of calcium hydroxide with alumina. Obviously, the hydrated OPC-A10 showed the lowest free lime contents, reaching $23.49 \%$ at the final hydration stages (28 days) compared with the hardened neat OPC, Table 5, (Ibrahim et al., 2018). Figure 13 illustrates the free lime content measures of the hardened neat and the hardened blended pastes at different hydration ages.

Table 5. Free Lime Content Measures of the Hardened Neat and the Hardened Blended Pastes at Different Hydration Ages

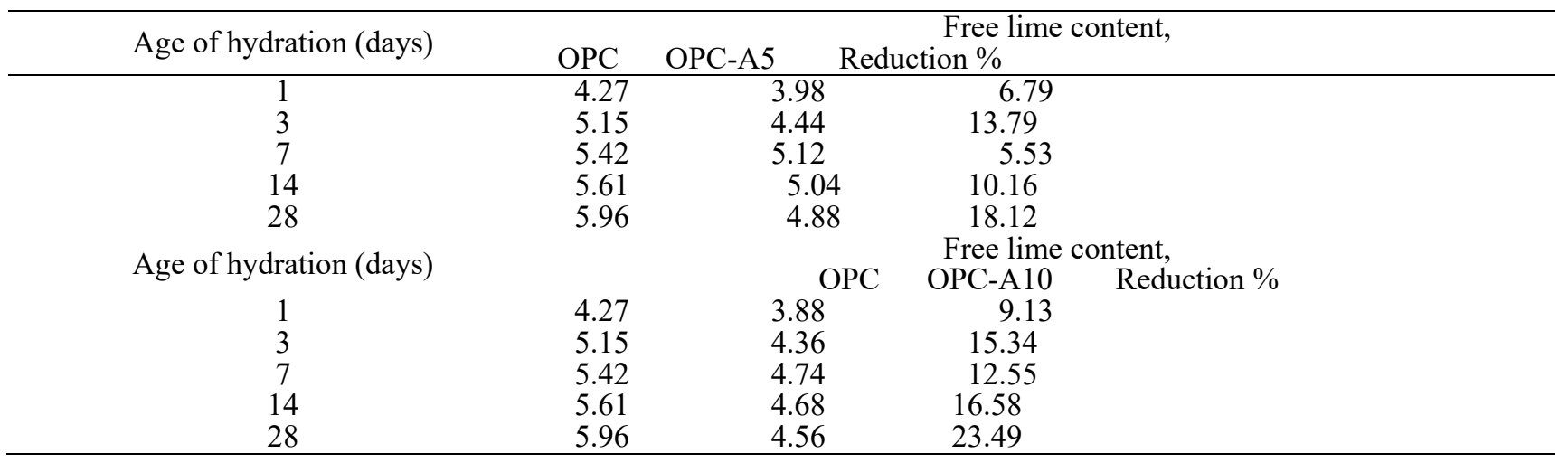

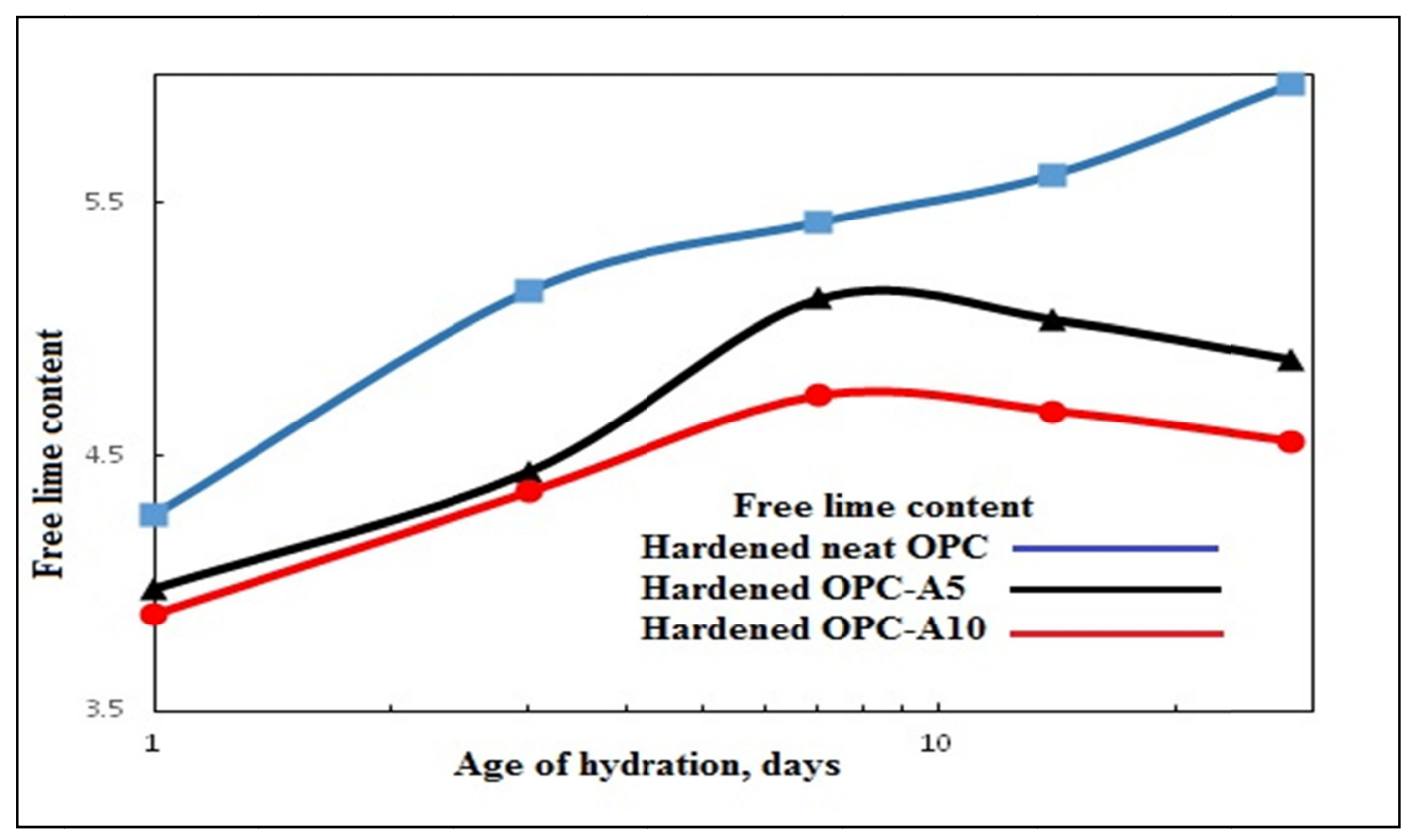

Figure 13. The Free Lime Content versus Age of Hydration

By comparing the compressive strength and the hydration kinetic measures of the OPC-A5 and OPC-A10, it was obvious that the addition of $5 \%$ alumina to the cement paste caused increasing in the compressive strength measures, in addition to its good effect on decreasing the amounts of the free lime values throughout all the ages of hydration, Figures 9 and 13.

The changes in different hydrated phases through the ages of hydration 1, 14 and 28 days of the hardened neat OPC and the OPC-A5 paste were followed up using the thermal gravimetric TG, the differential scanning calometric DSC and the differential thermogravimetric DTG thermograph analyses, Figures 14-19.

The DTA curves of the hardened neat OPC at 1,14 and 28 ages hydration show the occurrence of three main endothermic peaks: below $200^{\circ} \mathrm{C}, 380-450^{\circ} \mathrm{C}$ and $600-700^{\circ} \mathrm{C}$, Figures $14-16$. The endothermic peaks located below $200^{\circ} \mathrm{C}$ are mainly due to the dehydration of interlayer water of calcium silicate hydrate $\mathrm{CSH}$ and calcium aluminate hydrates $(\mathrm{CAH})$, whereas the endothermic peak at $380-450^{\circ} \mathrm{C}$ is due to the decomposition of calcium hydroxide $(\mathrm{CH})$, (Badogiannis, Kakali, Dimopoulou, Chaniotakis,\& Tsivilis, 2005). The endothermic peak located at $600-800^{\circ} \mathrm{C}$ is due to the decomposition of calcium carbonate $\left(\mathrm{CaCO}_{3}\right)$, (Rojas \& Sanchez de Rojas, 2004), Figures 14-16.

In case of 1 day of hydration, there are two other endothermic peaks at $200-350{ }^{\circ} \mathrm{C}$ and $800-950{ }^{\circ} \mathrm{C}$, Figure 14 . The 
endothermic peak $200-350{ }^{\circ} \mathrm{C}$ is mainly due to the dehydration of the calcium sulpho-aluminate hydrates (ettringite and mono sulphate hydrates), Figure 14. In case of 28 days of hydration, there is an endothermic peak between $500-550{ }^{\circ} \mathrm{C}$, Figure 16. It is clear that the intensities of the endothermic peaks characteristic for $\mathrm{CH}$ and $\mathrm{CaCO}_{3}$ increase with the increase of age of hydration up to 28 days due to progress of hydration of OPC pastes. Also, the endothermic peaks of $\mathrm{CSH}$ and CASH increase with the increase of the days of hydration due to progress of hydration, Figures 14-16.

The hydration progress can be studied from thermal gravimetric analysis (TG) data, Figures 14-16. The TG losses characteristics for the hydration products at low temperatures up to $200^{\circ} \mathrm{C}$ are about $2.00,2.50$ and 2.00 mass $\%$ after 1,14 and 28 days, respectively. This means that the degree of hydration is almost the same throughout all the ages of hydration with slight increase at the 14 days of hydration. On the other hand, the TG mass $\%$ loss characteristics for $\mathrm{CH}$ are 3.00, 5.50 and 5.00 mass\% after 1, 14 and 28 days, respectively. The increase of TG loss of portlandite with aging time is due to the continuous liberation of $\mathrm{CH}$ as a result of hydration of OPC. The TG losses due to the decomposition of $\mathrm{CaCO}_{3}$ are 4.00, 7.00 and 10 mass $\%$ after 1, 14 and 28 days, respectively. This increase in the mass $\%$ loss of the paste sample with increasing the days of hydration is attributed to the continuous liberation of $\mathrm{CH}$ and the reaction with $\mathrm{CO}_{2}$ forming $\mathrm{CaCO}_{3}$, Figures 14-16, (Mina'rik \& Kopecsko, 2013; Antoni, Rossen, Martirena,\& Scrivener, 2012; Esteves, 2011; Vedalakshmi, 2003).

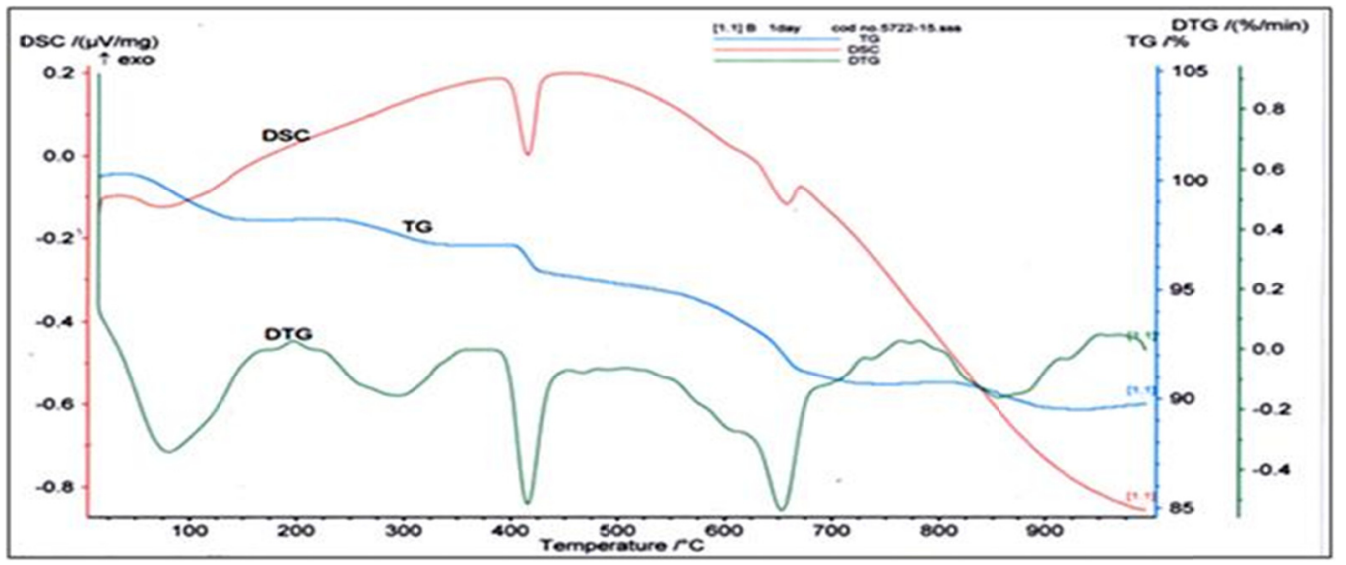

Figure 14. The Thermal Analysis of the Hydrated Neat OPC Paste at 1 Day of Hydration

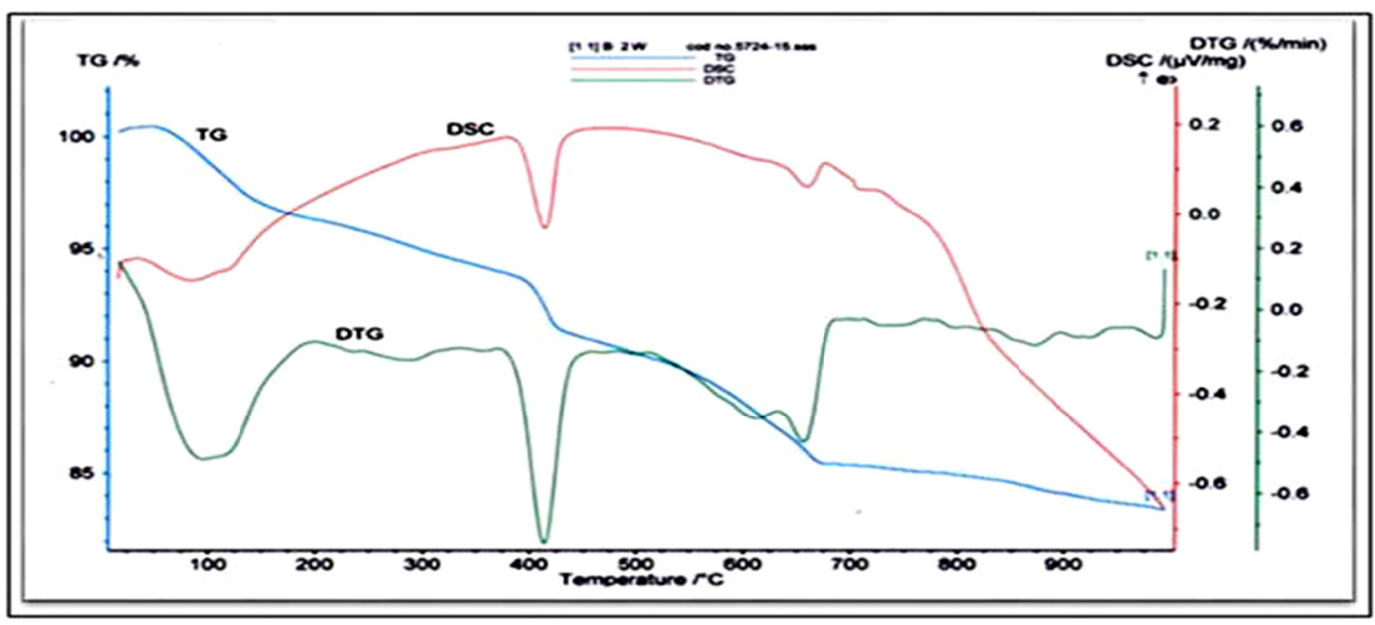

Figure 15. The Thermal Analysis of the Hydrated Neat OPC Paste at 14 Days of Hydration 


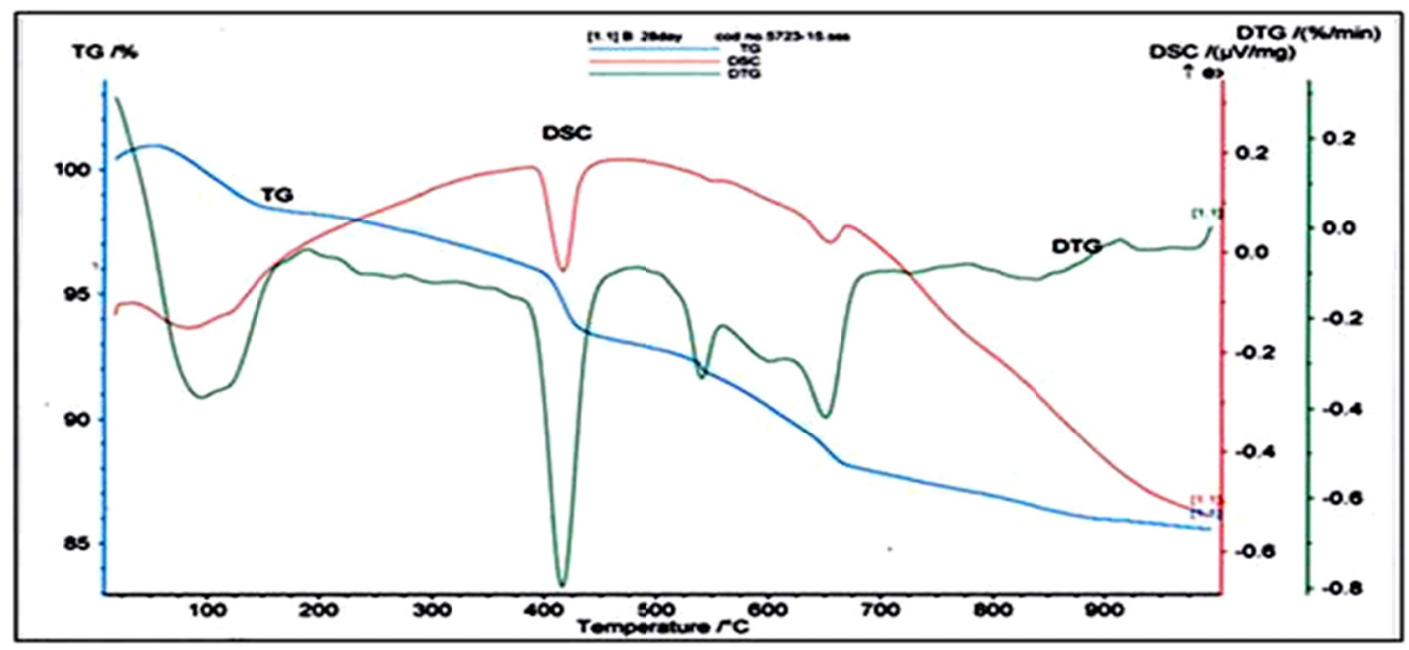

Figure 16. The Thermal Analysis of the Hydrated Neat OPC Paste at 28 Days of Hydration

The DTA curves of the hydrated OPC-A5\% at 1, 14 and 28 days of hydration are shown in Figures 17-19. Evidently, there are four endothermic peaks. The first endothermic peak located at $100{ }^{\circ} \mathrm{C}$ is mainly due to the removal of free water and the decomposition of the amorphous part of calcium silicate hydrates $(\mathrm{C}-\mathrm{S}-\mathrm{H})$. The second endothermic peak observed at about $150-250{ }^{\circ} \mathrm{C}$ represents the decomposition of the crystalline part of $\mathrm{CSH}, \mathrm{CAH}, \mathrm{CASH}$ as well as the presence of carboaluminate and gehlenite hydrates, (Wittmann, Kantor, Belafi, Peterfy,\& Farkas, 1992). The third endotherm located at $400-450{ }^{\circ} \mathrm{C}$ represents the dehydration of calcium hydroxide (CH), (Badogiannis et al., 2005; Elena et al., 2016). The last endothermic peak located at $550-700{ }^{\circ} \mathrm{C}$ is due to decomposition of $\mathrm{CaCO}_{3}$, (Rojas \& Sanchez de Rojas, 2004; Badogiannis et al., 2005).

It is clear that the second endothermic peak located at about $155{ }^{\circ} \mathrm{C}$ increases with aging time due to the formation of excessive amounts of $\mathrm{CAH}$ and $\mathrm{CASH}$ on the expense of $\mathrm{CSH}$. These phases are formed as a result of the pozzolanic reaction of 5\% alumina with $\mathrm{CH}$. The main features of the curves are characterized by the relative increase of the peak areas characteristic for $\mathrm{CH}, \mathrm{CAH}, \mathrm{CASH}$ and $\mathrm{CSH}$ phases as the hydration time increases up to 28 days of hydration; this is due to the fact that the small amount of alumina acts as nucleation agent which enhances the hydration process. The endothermic peak located at $600-700{ }^{\circ} \mathrm{C}$ is mainly due to the decomposition of $\mathrm{CaCO}_{3}$, Figures 17-19.

The TG curves of hydrated 5\% alumina pozzolanic cement pastes (OPC-A 5\%) cured up to 28 days show that the mass losses of the hydrated phases up to $200{ }^{\circ} \mathrm{C}$ are $4.00,12.00$ and $2.50 \%$ for OPC-A $5 \%$ blend hydrated for 1,14 and 28 days, respectively, Figures 17-19. The TG losses of hydrated cement paste made of OPC-A5\% blend due to the dehydration of portlandite $\left(400-450{ }^{\circ} \mathrm{C}\right)$ are $10.00,15.00$ and 7.00 mass $\%$ for 1,14 and 28 days of hydration, respectively. This indicates that 5 mass $\%$ MK acts as nucleating agent which accelerates the rate of hydration of OPC comparing to the hydrated neat OPC (3.00, 5.50 and 5.00 mass \% for 1, 14 and 28 days of hydration, respectively). However, it could be noted also that the hydration process after adding $5 \%$ alumina is highly accelerated, especially through the early stages of hydration, and this is followed by a relative inactivity at the late stages of hydration, Figure 17. This phenomenon is confirmed by measuring the mass losses of the hydrated OPC-A $5 \%$ due to the decomposition of $\mathrm{CaCO}_{3}$ throughout the different ages of hydration which recorded 10, 5 and 1 mass\% loses at 1, 14 and 28 days of hydration, respectively, Figures 17-19. The high TG loses of $\mathrm{CaCO}_{3}$ at the early stages of hydration indicates the high pozzolanic activity of the added $5 \%$ alumina at the early stages of hydration due to the active carbonation of portlandite. 


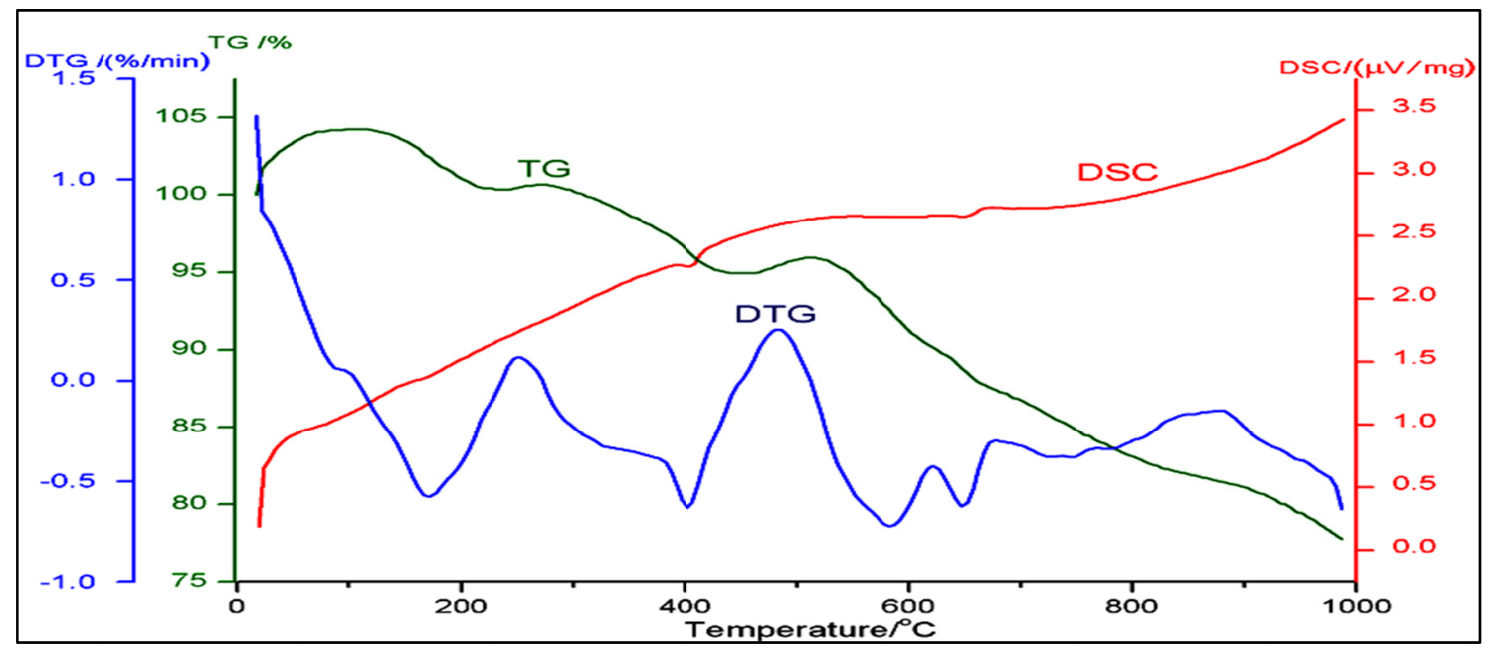

Figure 17. The Thermo-grams Curves of the Hardened OPC-A5 after 1 Day

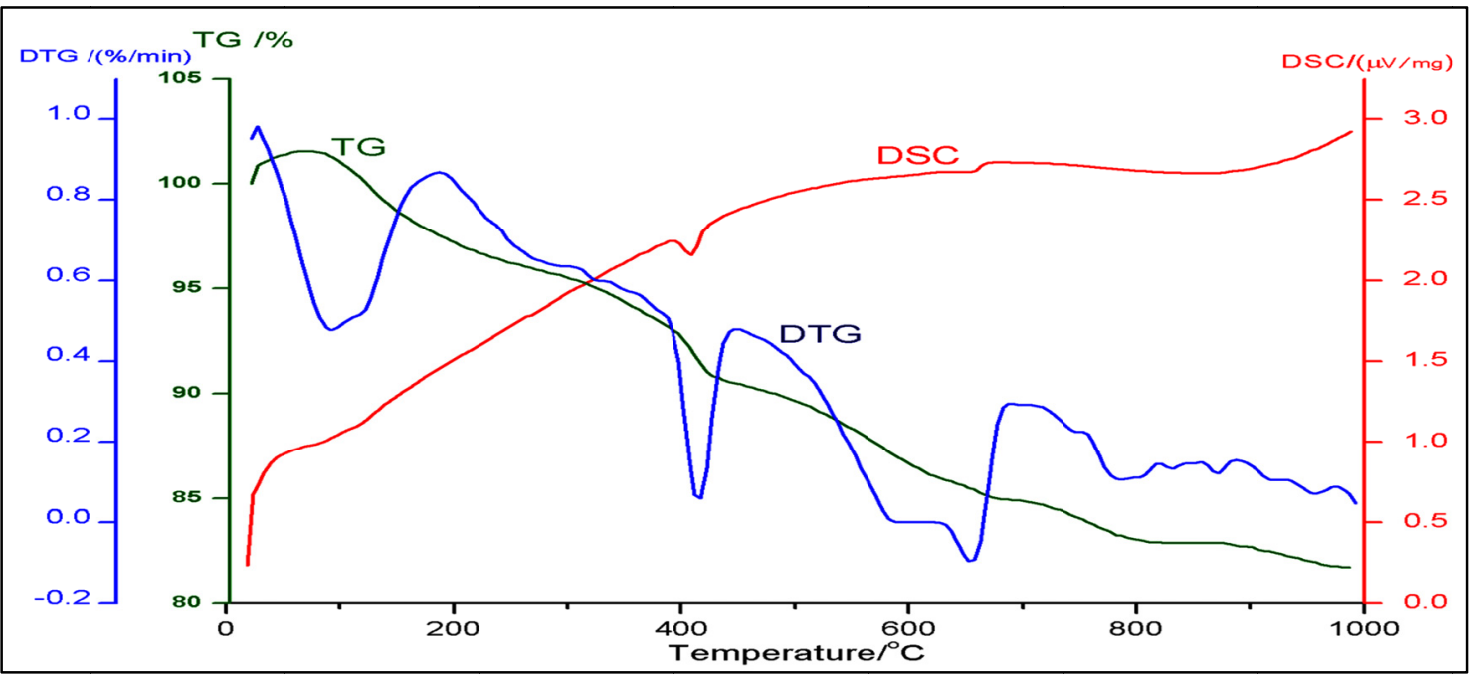

Figure 18. The Thermo-grams Curves of the Hardened OPC-A5 Paste after 14 Days

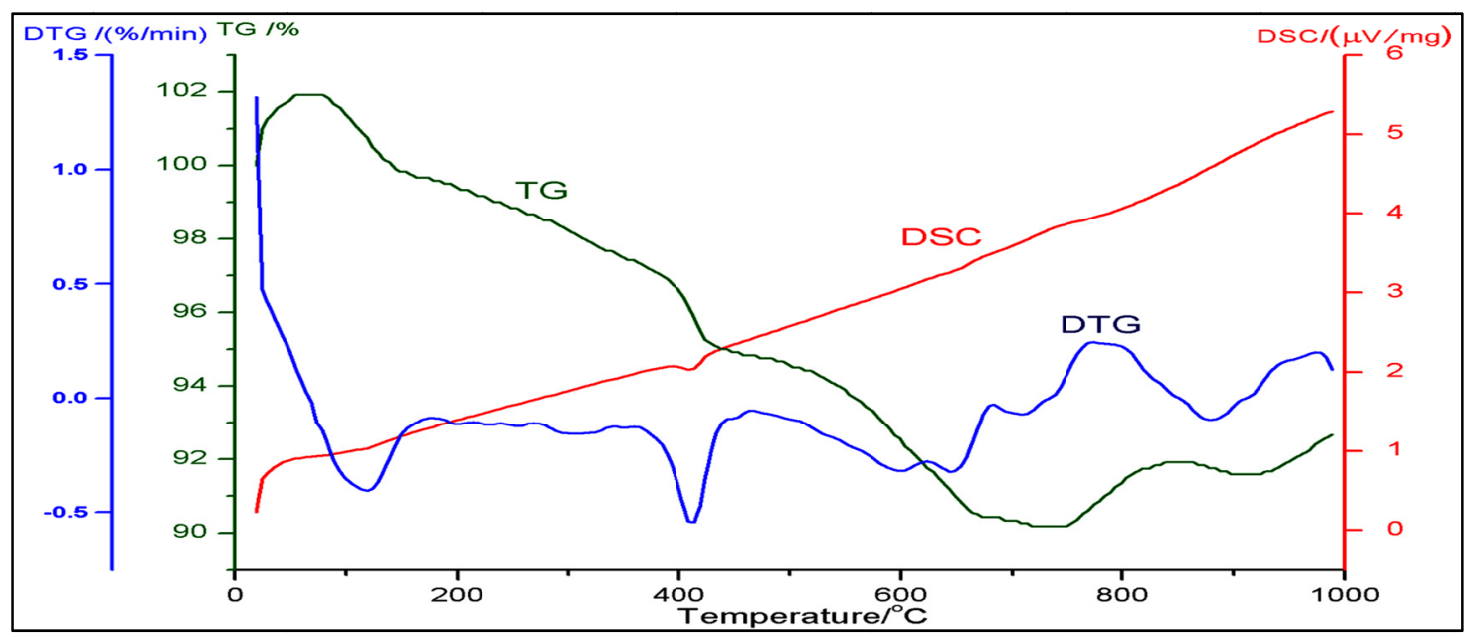

Figure 19. The Thermo-grams Curves of the Hardened OPC-A5 Paste after 28 Days 


\section{Conclusions}

- Significant improvements in the physico-mechanical properties and the hydration characteristics of the cement pastes were recorded after blending them with 5\% and $10 \%$ recycled alumina waste.

- The initial and final setting times of the blended cement pastes were reduced significantly after alumina addition.

- The optimum replacement of OPC for the improvement of hydraulic properties of blended cement pastes is $5 \%$ alumina. The replacement of alumina causes a marked improvement of the strength and the microstructure of the blended pastes, especially at the early stages of hydration.

- The DSC thermo-grams and XRD analysis for the investigated cement blended pastes indicated the formation of nearly amorphous calcium silicates, calcium sulpho-aluminate hydrates, calcium aluminate hydrates and portlandite.

- The SEM micrographs showed that the partial substitution of OPC by $5 \%$ alumina in the early stages of hydration leads to the formation of the denser structure calcium sulpho-aluminate hydrate (AFm) which strengthens the cement paste body.

- The improvement in the physical and the mechanical characteristics in addition to the hydraulic properties of the cement paste body in the early ages of hydration after 5\% alumina addition is important in many concrete applications, such as high-speed construction, rapid repair, frost prevention, tunneling, shoring, gas and oil well cementing, that require concrete to have rapid setting and strength development abilities.

\section{Acknowledgement}

The linguistic correction of the text carried out by Mrs. Brenda Cruise, the former Principal Administrative Assistant of a multinational American company, is much appreciated.

\section{References}

Abo-El-Enein, S. A., Abbas, R., \& Ezzat, E. (2010). Properties and durability of metakaolin blended cements. Materiales de Construcción, 60(299), 21-35. https://doi.org/10.3989/mc.2010.50509

Abo-El-Enein, S. A., Amin, M. S., El-Hosiny, F. I., Hanafi, S., El Sokkary, T. M., \& Hazem, M. M. (2014). Pozzolanic and hydraulic activity of nano-metakaolin. Housing and Building National Research Centre, 10, 64-72. https://doi.org/10.1016/j.hbrcj.2013.09.006

Al'myasheva, V. O., Korytkova, N. E., Maslov, V. A., \& Gusarov, V. V. (2005). Preparation of nanocrystalline alumina under hydrothermal conditions. Inorganic Materials, 41(5), 460-467. https://doi.org/10.1007/s10789-005-0152-7

Amer, A. A., \& El-Hoseny, S. (2017). Properties and performance of metakaolin pozzolanic cement pastes. Journal of Thermal Analysis and Calorimetry, 129, 33-44. https://doi.org/10.1007/s10973-017-6087-9

Amin, M. S., El-Gamal, S. M. A., \& Hashem, F. S. (2013). Effect of addition of nano-magnetite on the hydration characteristics of hardened Portland cement and high slag cement pastes. Journal of Thermal Analysis and Calorimetry, 125, 3-9. https://doi.org/10.1007/s10973-012-2663-1

Antoni, M., Rossen, J., Martirena, F., \& Scrivener, K. (2012). Cement substitution by a combination of metakaolin and limestone. Cement and Concrete Research, 42(12), 1579-1589. https://doi.org/10.1016/j.cemconres.2012.09.006

Arefi, M. R., Javeri, M. R., \& Mollaahmadi, E. (2011). To study the effect of adding $\mathrm{Al}_{2} \mathrm{O}_{3}$ nanoparticle on the mechanical properties and microstructure of cement mortar. Life Science Journal, 8(4), 613-617. (ISSN: 1097-8135). http://www.lifesciencesite.com.

Badogiannis, E., Kakali, G., Dimopoulou, G., Chaniotakis, E., \& Tsivilis, S. (2005). Metakaolin as a main cement constituent. Exploitation of poor Greek kaolins. Cement and Concrete Composition, 27(2), 197-203. https://doi.org/10.1016/j.cemconcomp.2004.02.007

Baranyai, V., Kristály, F., \& Szücs, I. (2013). Influence of the short time grinding on the thermal decomposition processes of gibbsite produced by the Bayer process. Materials Science and Engineering, 38(1), 15-27. https://www.researchgate.net/publication/235754150

Chukin, G. D., \& Seleznev, Y. L. (1989). Mechanism of the thermal decomposition of boehmite and a structural model of aluminum oxide. Kinetics and Catalysis, 30(1), 69-77.

Egyptian specification (2020). The standard methods for the chemical analysis.

El-Diadamony, H., Amer, A. A., Sokkary, T., \& El-Hoseny, S. (2016). Hydration and characteristics of metakaolin pozzolanic cement pastes. Housing and Building National Research Center. https://doi.org/10.1016/j.hbrcij.2015.05.005 
Erdem, E., Gunay, M. E., \& Donat, R. (2003). Hydration and mechanical properties of Portland cement containing eloxal waste from aluminum industry. Journal of Materials Processing Technology, 136, 35-38. https://doi.org/10.1016/S0924-0136(02)00839-7

Esteves, L. P. (2011). On the hydration of water-entrained cement-silica system combined SEM, XRD and thermal analysis in cement pastes. Thermochim Acta, 518(1), 27-35. https://doi.org/10.1016/j.tca.2011.02.003

Farzadnia, N., Ali, A. A., \& Demirboga, R. (2013). Characterization of high strength mortars with nano alumina at elevated temperatures. Cement and Concrete Research, 54, 43-54.

https://doi.org/10.1016/j.cemconres.2013.08.003

Federica, L., Elena, R., \& Luca, B. (2016). A study on the applicability of the efficiency factor of supplementary cementitious materials to durability properties. Construction and Building Materials, 120, 284-292. https://doi.org/10.1016/j.conbuildmat.2016.05.031

Gitzen, H. W. (1970). Alumina as a ceramic material. Columbus, Ohio: American Ceramic Society.

Han, J., Wang, K., Shi, J., \& Wang, Y. (2014). Influence of sodium aluminate on cement hydration and concrete properties. Construction and Building Materials, 64, 342-349. https://doi.org/10.1016/j.conbuildmat.2014.04.089

Hayrapetyan, S. S., Mangasaryan, L. G., Tovmasyan, M. R., \& Khachatryan, H. G. (2006). Precipitation of aluminum hydroxide from sodium aluminate, by treatment with formalin, and preparation of aluminum oxide. Acta Chromatographica, 16, 192-203.

http://www.akademiai.com/content/121093/http://acta-chromatographica.us.edu.pl/

Heikal, M., Ismail, M. N., \& Ibrahim, N. S. (2015). Physico mechanical, microstructure characteristics and fire resistance of cement pastes containing $\mathrm{Al}_{2} \mathrm{O}_{3}$ nano-particles. Construction and Building Materials, 91, 232-242. https://doi.org/10.1016/j.conbuildmat.2015.05.036

Ibrahim, S. S., Hagrass, A. A., Boulos, R. T., Youssef, I. S., El Hossiny, I. F., \& Moharam, R. M. (2018). Metakaolin as an active pozzolan for cement that improves its properties and reduces its pollution hazard. Journal of Minerals and Materials Characterization and Engineering, 6, 86-104. https://doi.org/10.4236/jmmce.2018.61008

Kazakov, S. V., Sokolov, A. N., \& Tsiporina, S. Z. (1988). Aluminum oxide with mullite structure. Izv. Akad.Nauk SSSR, Neorg. Mater., 24(12), 2010-2013.

Kiachehr, B., \& Niloofar, S. (2013). The effects of nano-silica and nano-alumina on frost resistance of normal concrete. Construction and Building Materials, 48, 580-584. https://doi.org/10.1016/j.conbuildmat.2013.07.088

Li, Y. S., Lima, D. S., Chunb, B. S., \& Ryou, J. S. (2013). Characterization of a sodium aluminate $\left(\mathrm{NaAlO}_{2}\right)$ - based accelerator made via a tablet processing method. Journal of Ceramic Processing Research, 14(1), 87-91.

Mardilovich, P. P., Trokhimets, A. I., Zaretskii, M. V., \& Kupchenko, G. G. (1985). IR spectroscopic study of bayerite and hydrargillite dehydration. Zh. Prikl. Spektrosk, 42(6), 959-966.

Mina'rik, L., \& Kopecsko', K. (2013). Impact of metakaolin -a new supplementary material on the hydration mechanism of cement. Acta Technica Napocensis: Civil Engineering \& Architecture, 56(2), 100-110. http://constructii.utcluj.ro/ActaCivilEng

Mobili, A., Belli, A., Giosuè, C., Bellezze, T., \& Tittarelli, F. (2016). Metakaolin and fly ash alkali-activated mortars compared with cementitious mortars at the same strength class. Cement and Concrete Research, 88, 198-210. https://doi.org/10.1016/j.cemconres.2016.07.004

Morsy, S. M., \& Shebl, S. S. (2007). Sayed, Effect of Silica Fume and metakaolin pozzolana on the performance of blended cement pastes against fire. Ceramics- Silikáty, 51(1), 40-44. https://www.researchgate.net/.../279713870_Effect_of_silica_fume_and_metakaoline_p

Nazari, A., \& Riahi, S. (2011). $\mathrm{Al}_{2} \mathrm{O}_{3}$ nanoparticles in concrete and different curing media. Energy and Buildings, 43, 1480-1488. https://doi.org/10.1016/j.enbuild.2011.02.018

Nazari, A., Riahi, S., Shamekhi, S., \& Fand, K. A. (2010). Influence of $\mathrm{Al}_{2} \mathrm{O}_{3}$ nanoparticles on the compressive strength and workability of blended concrete. Journal of American Science, 6, 6-9. Journal of American Science, 6(5), 6-9.

Nehdi, M., \& Hayek, M. (2005). Behavior of blended cement mortars exposed to sulfate solutions cycling in relative humidity. Cement and Concrete Research, 35, 731-742. https://doi.org/10.1016/j.cemconres.2004.05.032

Onutai, S., Jiemsirilers, S., Wada, S., \& Thavorniti, P. (2014). Effect of sodium hydroxide solution on the properties of geopolymers of based on fly ash and aluminium waste blend. Suranaree Journal of Science Technology, 21(1), 9-14. iopscience.iop.org/article/10.1088/1757-899X/343/1/012013 
Park, Y. S., Suh J. K., Lee J. H., \& Shin Y. S. (1999). Strength deterioration of high strength concrete in sulfate environment. Cement and Concrete Research, 29, 1397. https://doi.org/10.1016/S0008-8846(99)00106-4

Rojas, M. F., \& Sanchez de Rojas, M. I. (2004). Chemical assessment of the electric arc furnace slag as construction material: expansive compounds. Cement and Concrete Research, 4(10), 1881-1888. https://doi.org/10.1016/j.cemconres.2004.01.029

Vedalakshmi, R. (2003). Quantification of hydrated cement products of blended cements in low and medium strength using TG and DTA technique. Thermochim Acta, 407(1-2), 49-60. https://doi.org/10.1016/S0040-6031(03)00286-7

Wittmann, Z., Kantor, E., Belafi, K., Peterfy, L., \& Farkas, L. (1992). Phase composition analysis of hydrous aluminium oxides by thermal analysis and infrared spectrometry. Talanta, 39, 1583-1586. https://doi.org/10.1016/0039-9140(92)80187-I

Zelie, J., Rusie, D., Veza, D., \& Krestulovie, R (2000). Cement and Concrete Research, 30, 1655. https://doi.org/10.1016/S0008-8846(00)00374-4

\section{Copyrights}

Copyright for this article is retained by the author(s), with first publication rights granted to the journal.

This is an open-access article distributed under the terms and conditions of the Creative Commons Attribution license (http://creativecommons.org/licenses/by/4.0/). 